International Journal of Engineering \& Technology, 9(3)(2020) 785-803
International Journal of Engineering \& Technology
SPC
Website: www.sciencepubco.com/index.php/IJET
Research paper

\title{
Estimation of porosity of rocks based upon axiomatic local linear model tree (a lolimot model) approach
}

\author{
Hossein Iranmanesh $^{1}$, Ali Mollajan ${ }^{2}$ \\ ${ }^{1}$ School of Industrial Engineering, College of Engineering, University of Tehran \\ ${ }^{2}$ School of Industrial Engineering, College of Engineering, University of Tehran, Tehran, Iran \\ *Corresponding authorE-mail: hiranmanesh@ut.ac.ir
}

\begin{abstract}
Shear and Compressional Wave Velocities along with other Petrophysical Logs, are considered as upmost important data for Hydrocarbon reservoirs characterization. In this study, porosity of the extracted rocks form concerned wells is interest as it can indicate the oil capacity of the wells of interest. In this study, we employ the principles of Axiomatic Design theory, specially the first (independence) axiom, to more simplify the measurement system. Also, to clarify the strength of Axiomatic Design theory in reducing the complexity of the system and optimizing the measurement system, we utilize the The Lolimot model (LOcal LInear MOdel Tree) as a model from the neural network family and apply it before and after implementing the basic logic of Axiomatic Design (AD) theory. In addition, in order to illustrate strength of the proposed method emphasizing the effectiveness of a method which benefit from both AD theory and Lolimot model together, the existing system used to measure the rock porosity is addressed and actual data related to one of wells located in southern Iran is utilized. The results of the study show that integrating the Axiomatic Design principles with the LOLIMOT method leads to the least complex and most accurate results.
\end{abstract}

Keywords: Axiomatic Design Theory; Fuzzy Linear Regression; Local Linear Model Tree (Lolimot Model) Rocks Prosoity.

\section{Introduction}

In rock engineering, methodologies based on wave velocity are increasingly used to determine the dynamic properties of rocks (Singh et al., 2012). In Petroleum engineering context, this is mainly due to very sparse or no borehole-based rock mechanical data being acquired during drilling phase. This is while having this information is essential for reservoir development, management, and prospect evaluation in exploration areas (Ameen et al., 2009). The direct measurements of the geomechanical properties of formations need testing core samples in the lab. However, limited number of samples can be taken from the whole wellbore interval (of few thousands meter) due to cost and technical issues. In addition to the fact that lab experiments are time consuming and also expensive to be conducted, the results obtained from testing only few number of samples cannot provide a good estimation of mechanical properties of formations crossed by the wellbore. Indeed, it would be ideal to have continuous logs, similar to petrophysical logs, representing elastic and strength properties of different formations.

Body waves are categorized to compressional and shear waves. Shear or S-waves do not propagate through fluids and when associated with compressional waves, can provide useful information for hydrocarbon reservoirs characterization. There are many factors that affect seismic velocities. However investigations show that Vs is strongly controlled by compressional velocities, type of pore fluid, clay content, and bulk density of the rock (reviewed in Rezaee, 2001).

There are many applications for S-waves in petrophysical, seismic and geomechanical studies. For example Vp/Vs ratio can be used as a key factor to characterize some important reservoir properties such as lithology, pore fluid type, degree of reservoir consolidation and in AVO and VSP studies.

Compressional wave velocity can be obtained directly from sonic transit time. But Vs either is measured at the laboratory on core samples or by means of Dipole Shear Sonic Imager tool (DSI). Most wells (especially old wells), do not have DSI data.

Although empirical relationships are useful methods to calculate Vs, but they have limitations and disadvantages that are listed below:

a) Most of the empirical methods have been developed for sandstone reservoirs and are not efficient for all lithologies.

b) All available empirical models are mathematical models that have used limited petrophysical inputs, so they miss the generalization capability (Eskandari et al., 2004). So, it will be efficient and useful to predict Vs utilizing fast and robust intelligent systems from well $\log$ data.

According to the studies carried out to estimate mechanical properties of subsurface layer, having shear velocity data is necessary to make reliable calculations (Ameen et al., 2009; Boonen et al., 1998; Eissa and Kazi, 1988; Rasouli et al., 2011; Zoback, 2007). However, in practice the shear sonic is not included in the set of acquired logs but only compressional sonic is available. In such occasions, several methodologies have been proposed to make an estimation of shear sonic data from other available data. For example, Wantland (1964) 
assumed Poisson's ratio for reservoir rocks and estimated shear wave velocities. However, Poisson's ratio is changing in a wide range in practice; hence the accuracy of estimated shear sonic data is questionable (Carroll, 1969). Another approach is to measure elastic properties of rocks through acoustic measurements of Vp and Vs using pulse transmission techniques in laboratory (Birch, 1960; Christensen, 1974; Kern, 1982; Burlini

and Fountain, 1993; Ji and Salisbury, 1993; Watanabe et al., 2007). However, few lab data are available for Vs measurements compared to those of $\mathrm{Vp}$ ( Ji et al., 2002). This is mainly due to the difficulties of Vs measurements at low pressures, as the transmission of shear wave through the sample requires a firm contact between the transducers and the end surfaces of the specimen. Since variations of shear wave velocity are related to the rock type, mechanical properties and loading conditions, the laboratory measurements cannot ideally simulate downhole field conditions (e.g. in situ stresses and fluid content). The use of a large range of empirical correlations has been reported during the last decades to estimate shear wave velocity from rock physical parameters (Castagna et al., 1993; Brocher, 2005, 2008; Ameen et al., 2009; Yasar and Erdogan, 2004). However, these correlations have been developed for a specific area and their use in other fields is subjected to uncertainties.

In recent years, artificial intelligence (AI) methods have been used widely for prediction purposes (Feng, 1995; Mohammadi and Rahmannejad, 2009; Zhang et al., 2009). Once the network has been trained, it can make prediction, based on its previous learning, about the output related to new input data set of similar pattern. Support Vector Regression (SVR) is usually used as an efficient machine learning methodology for prediction of rock properties (Annan and Chunan, 2008; Kang and Wang, 2010; Niu and Li, 2010; Rechlin et al., 2011; Wenlin et al., 2011). The SVR relies on the statistical learning theory enabling learning machines to generalize the unseen data. This technique has proven to have superior performances in a variety of problems due to its generalization abilities and robustness against noise and interferences (Steinwart, 2008). SVM is a device for finding a solution which uses the minimum possible energy of the data (MartinezRamon and Cristodoulou, 2006; Cristianini and Shawe-Taylor, 2000). In general, there are at least three reasons for the success of SVM: its ability to learn well with only a very small number of parameters, robustness against the error of the model, and its computational efficiency compared with several other methods such as neural network and fuzzy network (Martinez-Ramon and Cristodoulou, 2006). In this paper, petrophysical logs corresponding to a well drilled in the southern part of Iran were used to estimate the shear wave velocity using empirical correlations as well as novel AI techniques. Such basic information are regarded as required input to predict the porosity of rocks extracted from the concerned wells. However, despite the considerable strength of Artificial Intelligence methods, it seems that they are not good enough to significantly reduce the complexity of the system. In this line of thought, we show how fundamentals of the so called "Axiomatic Design (AD)" along with the AI methods could play their remarkable roles.

Originally, AD was introduced by Suh (1990-2001) in order to design effective physical and mechanical systems. However, because of rational, comprehensive, and strong principles of AD approach; we attempt to apply its fundamentals to the so called "Neuro Fuzzy Models", specially The Lolimot model (LOcal LInear MOdel Tree) as a model from the neural network Family.

\section{Geology of field}

This study uses the data belonging to an oilfield located in the Iranian Province of Khuzestan, onshore of the Ahwaz region, near the IranIraq frontier (see Fig. 1). The field is a North-South oriented gentle anticline, located in the Dezful Embayment, which is a sector associated with the closing of the Neo-Tethys sea and the Tertiary formation of the Zagros- Taurus Mountains. The oilfield is close the Basrah area in the west. The structures in the Basrah area consist of gentle anticlines showing a North-South general trend which is the same to this field. The trend of these anticlines follows the old North-South oriented basement lines. The presence of Precambrian and Early Cambrian salt in Northern Persian Gulf area and Saudi Arabia is considered as a reason to explain the possible origin of these structures. However the development of these anticlines seems related to the reactivation of basement faults which can be responsible for their structural evolution. The structural growth of the field area may be already started during the Mesozoic or earlier and continued through the time.

The Fahliyan Formation is well exposed in the Zagros Mountains, in Fars province (James and Wynd, 1965). At the same time of the sedimentation of the Fahliyan, in the area located between the oilfield and the Khuzestan province, the intra-shelf basin of the Garau Formation takes place. The current oilfield area at the time of the Fahliyan sedimentation must have belonged to an articulate carbonate ramp complex, partly controlled by local tectonics, partly by sea level changes, probably limited Eastward by a more subsiding area underwent a deeper sedimentation. Argillaceous limestones and shales of deep environment also develop in Offshore Kuwait, suggesting that this area belonged to the same intra-shelf basin. The sedimentation of these units is related to the significant sea level rise started during the late Tithonian and continued into the early Berriasian (Sadooni, 1993). The shallow water sequences of Fahliyan and equivalent units of northern Persian Gulf underlay the shale and bioclastic limestone of the Ratawi Formation. Fig. 1 shows the approximate geographical location of the oil field in Iran.

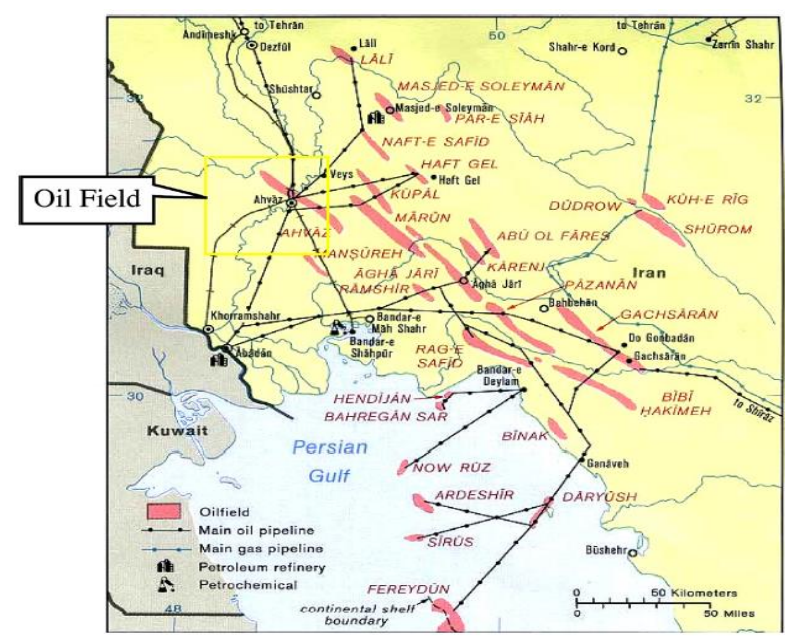

Fig. 1: Geographical Location of the Study Area. 
The middle and upper Cretaceous sediments of the Dezful Embayment form one of the richest petroleum systems in the Middle East, with the presence of the Gurpi, Khazdumi and

Gadvan source rocks and the Lurestan, Asmari, Khuzestan and Khami/Bangestan reservoirs (see Fig. 2).

\section{Well A}

The available well log data of the current study are belonging to a vertical wellbore drilled into a carbonate reservoir in southern part of Iran. The digitized well logs consist of dipole shear sonic imager (DSI), compressional wave sonic log (DTCO), gamma ray log (CGR), density $\log (\mathrm{ROHZ})$, effective porosity (PHIT), true formation resistivity log (RT), and caliper logs (HCAL). Fig. 3 shows well logs used for the purpose of this study.

The plot of shear wave velocity versus different conventional well logs is shown in Fig.s 2-5. As it is depicted in these Fig.s, a fair correlation was found between shear velocity and density logs (Fig. 2). There was also a correlation coefficient of 0.39 obtained between shear wave velocities with gamma ray (Fig. 3) while a correlation coefficient of 0.94 was observed between shear and compressional wave velocities (Fig. 4). It is obvious that there is a strong correlation between the shear and compressional wave velocity data of this well. Hence a correlation obtained by cross plotting of these two waves may have application for other wells located in this field where DSI data were not acquired for them. This correlation is presented as:

VS 1/4 0:4584VP p 0:3904 ð1P

In this equation, Vs and Vp are, respectively, shear and compressional wave velocities and unit of Vs and $\mathrm{Vp}$ is $\mathrm{km} / \mathrm{s}$ (kilometers to second).

\section{Literature review}

\subsection{Fuzzy linear regression}

The Fuzzy Linear Regression (FLR) approach was introduced by Tanaka et al. (1982 and 1992) in order to deal with a vague phenomenon. The assumptions of Tanaka's model include (i) the input and output data of fuzzy linear model are fuzzy, (ii) the relationship between the input and output data is given by a fuzzy function, and (iii) the distribution of the data is possibilistic (Peters, 1994). The fuzzy linear regression has been applied to forecasting in an uncertain environment for finding an interrelationship between the linear interval model and the output intervals of the given data. Tanaka's model assumes a linear function as Equation 1.

$Y=A_{0} \cdot x_{0}+A_{0} \cdot x_{0}+\cdots+A_{0} \cdot x_{0}=A \cdot X ;\left(x_{0}=1\right)$

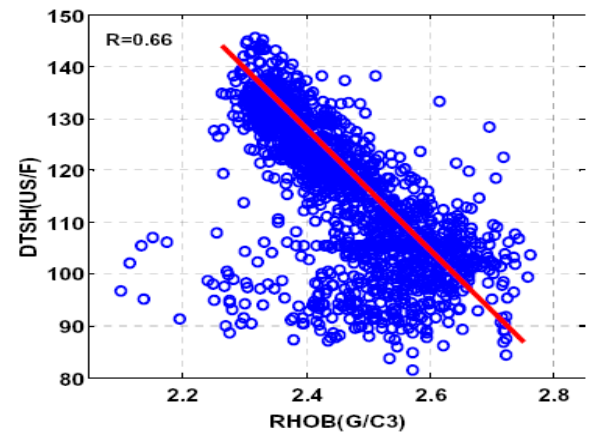

Fig. 2: Shear-Wave Velocity (US/F = Microsecond to Foot) Versus Density (RHOB).

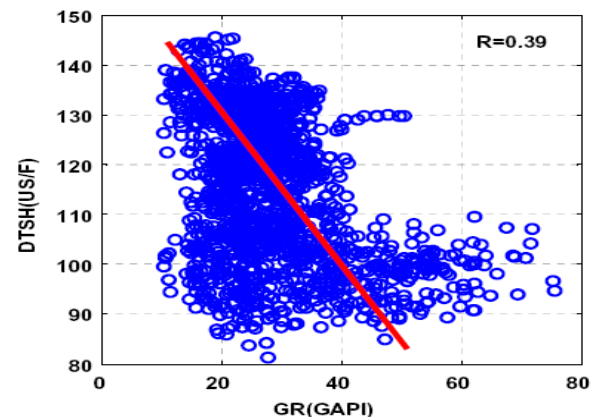

Fig. 3: Shear-Wave Velocity (US/F = Microsecond to Foot) Versus Gamma-Ray. 


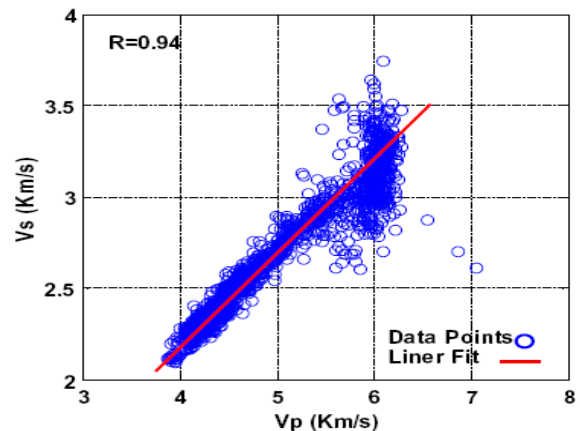

Fig. 4: Shear-Wave Velocity (Km/S = Kilometers to Second) Versus Compressional-Wave Velocity.

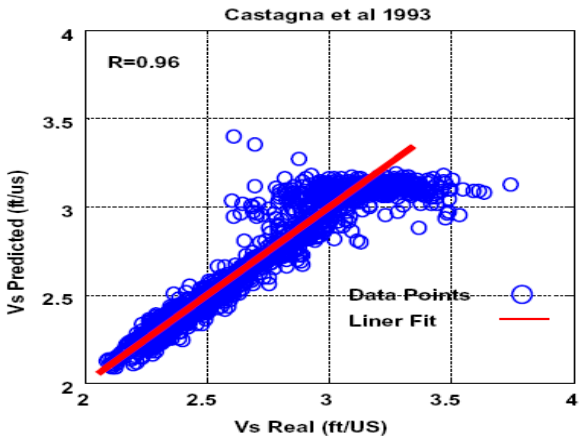

Fig. 5: Comparison of Real Versus Predicted Shear Wave Velocity (Using Castagna Correlation) in the Studied Wellbore (Ft/Us (Foot to Microsecond).

Where; $\mathrm{Y}$ is the dependent variable, $\mathrm{x}$ is the vector of the independent variables, and $\mathrm{A}$ is the vector of a fuzzy set on the product space of parameters. The fuzzy parameters, $A_{j}$, are represented in the form of triangular fuzzy numbers (Equation 1);

$A_{j}\left(a_{j}\right)=\left\{\begin{array}{c}1-\frac{\left|\alpha_{j}-a_{j}\right|}{c_{j}} ; \text { if } \alpha_{j}-a_{j} \leq a_{j} \leq \alpha_{j}+a_{j} \\ 0 ; \text { Otherwise }\end{array}\right.$

Where; $A_{j}\left(a_{j}\right)$ is the membership function of the fuzzy set of $a_{j}, \alpha_{j}$ is the center, and $c_{j}$ is the spread of the fuzzy number. According to Peters (1994), the membership degree of $Y$ can be obtained as Equation 3;

$Y(t)=\left\{\begin{array}{c}1-\frac{\left|y-X^{t} \cdot \alpha\right|}{C^{t} \cdot|X|} ; X \neq 0 \\ 1 ; X=0, y \neq 0 \\ 0 ; X=0, y=0\end{array}\right.$

We minimize the total vagueness using Equation 4;

$\operatorname{MIN} \sum_{j=0}^{N}\left(C_{j} \cdot \sum_{i=0}^{M}\left|x_{i j}\right|\right)$

Where; $\mathrm{M}$ is the number of training samples.

As the membership value of each observation $y_{j}$ is greater than an imposed threshold, we have Equation 5;

$Y\left(y_{i}\right) \geq h ;$ for $i=1,2, \ldots, M$

A linear programming problem is constructed as Equation 6;

$\operatorname{MIN} \sum_{j=0}^{N}\left(C_{j} \cdot \sum_{i=0}^{M}\left|x_{i j}\right|\right)$

Subject to

$\sum_{j=0}^{N} \alpha_{j} \cdot x_{i j}+\left|L^{-1}(h)\right| \cdot \sum_{j=0}^{N} C_{j} \cdot\left|x_{i j}\right| \geq y_{i}$

$\sum_{j=0}^{N} \alpha_{j} \cdot x_{i j}+\left|L^{-1}(h)\right| \cdot \sum_{j=0}^{N} C_{j} \cdot\left|x_{i j}\right| \leq y_{i}$

$C \geq 0, \alpha \in \Re, x_{i 0}=1$

$0 \leq h \leq 1$

$\mathrm{i}=1,2, \ldots, \mathrm{M}$

Where; $\left|\mathrm{L}^{-1}(\mathrm{~h})\right|=1-\mathrm{h}, \mathrm{h} \in[0,1]$, and the choice of the $\mathrm{h}$ value influences the widths $\mathrm{c}_{\mathrm{j}}$ of the fuzzy parameters. 
Tanaka's model can be used to analyze the interval of the dependent variable y, however, the drawback is that a few values may dominate the estimation of the bounds of the crisp interval. Therefore, the model is very sensitive to outliers (Peters 1994). Peters (1994) provided a modification to Tanaka's model. In this model, the bounds of the interval are assumed fuzzy rather than crisp, so that each of the dependent data y has a membership degree of belonging to the interval. Peters' fuzzy linear programming model is formulated as follows:

$$
\begin{aligned}
& \text { MA } \overline{\mathbf{X}}=\frac{1}{M} \sum_{i=1}^{M} \lambda_{Y} \\
& \text { Subject } \\
& \left(1-\left.\bar{\lambda}\right|_{p_{0}}-\sum_{i=0}^{M} \sum_{j=0}^{N} c_{j}\left|\chi_{i j}\right| \geq-d_{0}\right. \\
& \left(1-\lambda_{i}\right) p_{i}+\sum_{j=0}^{N} \alpha_{j} \chi_{i j}+\sum_{j=0}^{N} c_{j}\left|\chi_{i j}\right| \geq y_{i} \\
& \left(1-\lambda_{i}\right) p_{i}+\sum_{j=0}^{N} \alpha_{j} \chi_{i j}+\sum_{j=0}^{N} c_{j}\left|\chi_{i j}\right| \geq-y_{i} \\
& -\lambda_{Y} \geq-1 \\
& \lambda_{i}, c \geq 0, \alpha \in \Re \chi_{i 0}=1,\left|L^{1}(h)\right|=1 \\
& i=1,2 \cdots ; M
\end{aligned}
$$

where $\lambda$ represents the membership degree to which the solution belongs to the set "good solution". The value of $\lambda$ can be determined by a trade-off between the objective function and the equation of the "worst" datum y (Peters 1994) and $\mathrm{p}_{\mathrm{j}}$ is the width of the "tolerance interval".

A high value of $p_{0}$ and low values of $p_{i}$ leads to a wide interval; while a low value of $p_{0}$ and high values of $p_{i}$ leads to a narrow interval. In addition, $d_{0}$ represents the desired value of the objective function. The suggested value of $\mathrm{d}_{0}$ is 0 , since the total vagueness is desired to be 0 . The objective function allows for the training data of each instance to compensate the model. By the weight factor $1 / \mathrm{M}$, each training instance influences the regression function.

\subsection{Axiomatic design}

The "Axiomatic Design" (AD) method provides perspectives that usually overlooked by other design methods (El-Haik and Wasiloff, 2004). The "Axiomatic Design" has been built based upon four key elements of: (1) Domains; (2) Hierarchies; (3) zigzagging processes and finally (4) Axioms (Suh, 1990-2001).

- Domains

According to Suh (1990), the world of design consists of four domains as represented in Fig. 1. Each domain on the right side is, in fact, to answer how we can achieve the goals defined on its left adjacent domain, via appropriate mappings. "Customers' Attributes", CAs, are delineated in the "Customer Domain". CAs are, in fact, the STHs' needs which will be, next, specified in terms of "Functional Requirements", FRs, and "Constraints" (Cs). By definition, the "Functional Requirements", FRs, are a minimum set of independent requirements that are usually defined by engineering terms and are to completely characterize the functional needs of the product in the functional domain of the design. In addition, it should be noted that, always, these FRs should be established without thinking about what we need to satisfy the established FRs. That is, the FRs should be defined in a solution neutral environment. Further, in this stage, the "Cs" (e.g. Time, Cost, Production Rate, etc.) within which the product design has to be developed, should also be stated as well. This is, in fact, equivalent to "what we want to achieve." Next, as mentioned earlier, in order to fulfill the FRs, we also have to define or select physical solutions which are referred to as "Design Parameters", DPs, in the physical domain. Therefore, the DPs are, in fact, the critical physical variables in the physical domain that characterize the design which fulfills the specified FRs of the product under development. Often, this is referred to as "Physical Design" of the product intended to be developed. Finally, to manufacture/produce the product characterized in terms of DPs, we have to develop a process which is specified by "Process Variables" (PVs) in the process domain. To be more specific, the PVs are, in fact, the significant process variables in the process domain that characterize the process which manufacture/generate the specified DPs. Often, this is referred to as "Process Design" of the product intended to be developed (Suh, 1990-2001)

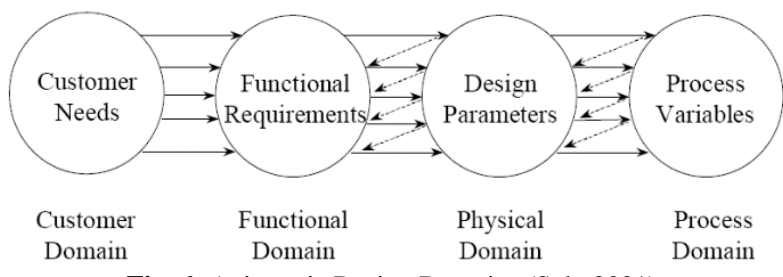

Fig. 6: Axiomatic Design Domains (Suh, 2001).

- "Hierarchies" and "Zigzagging Processes"

As stated earlier, "Hierarchies" and "Zigzagging Processes" are two key elements of the AD method for developing engineering systems and/or products. The "Hierarchical Decomposition" through "Zigzagging Processes between Domains", starts from the 'What' domain and, then, goes to the 'How' domain in order to conceptualize the product design and establish the corresponding with one previously 
identified in the "what" domain and it then comes back to the "what" domain to create sub-elements required at the next level of the product's levels of abstraction to collectively satisfy the highest level elements, in a top-bottom way, beginning at the system level, and continue through levels of more detail. Following identifying FRs and DPs at the top-level of the product (system)'s levels of abstraction, they should be decomposed till the product design reaches the final stage, the leaf level. Actually, at the leaf level, both FRs and DPs should not need either redesigning or further decomposition. The hierarchies established between FRs and DPs represent, in fact, the product design structure (Suh, 2001; Sharahi et al., 2015).

- Axioms:

Axiomatic Design pillars on two axioms proposed by Suh $(1990,2001)$ to govern the design process;

Axiom 1 - Is known as the "Independence Axiom". On the basis of this axiom, a good design of any system and/or product must maintain the independence of the FRs. This simply means that in case of mapping from the functional into the physical domain, the choice and allocation of the DPs should be made in such a way that each FR can be fulfilled without affecting other FRs. Similarly, if the mapping process occurs from the physical into the process domain, the PVs should be chosen and allocated in such a way that the independency among the DPs can be maintained normally (Suh, 2001). The mapping between two adjacent domains can be represented by a "Design Equation". In case of mapping from the functional to the physical domain, the design equation can be expressed as Equation 8;

$F R=[A] . D P$

Where; FR and DP are respectively the functional requirement vector and the design parameter vector, and [A] is the "Design Matrix" (DM) for this mapping. The DM displays the relationship between each $\mathrm{FR}_{\mathrm{i}}$ and each $\mathrm{DP}_{\mathrm{j}}$ (Equation 9);

$A_{i j}=\frac{\partial F R_{i}}{\partial D P_{j}}$

In addition, if there are m FRs and n DPs, the general format for the "DM" would be as Equation 10;

$D M=\left[\begin{array}{cccc}A_{11} & A_{1 j} & \cdots & A_{1 n} \\ A_{21} & A_{2 j} & \cdots & A_{2 n} \\ \vdots & \cdot & \ddots & \vdots \\ A_{m 1} & A_{m j} & \cdots & A_{m n}\end{array}\right]$

A square DM is obtained, with an equal number of FRs and DPs $(m=n),(F i g .2)$. If the DM is diagonal, the off-diagonal elements of this matrix can be assumed to be zero $\left(A_{i j} \cong 0\right.$, where $\left.\mathrm{i} \neq \mathrm{j}\right)$, and, therefore, an "Uncoupled Design" for the product and/or the system is obtained, and, as a result, the first axiom of AD can be satisfied (Suh, 2001).

The design equation to map physical domain to the process domain is given by Equation 11 .

$D M=\left[\begin{array}{cccc}A_{11} & A_{1 j} & \cdots & A_{1 n} \\ A_{21} & A_{2 j} & \cdots & A_{2 n} \\ \vdots & \cdot & \ddots & \vdots \\ A_{m 1} & A_{m j} & \cdots & A_{m n}\end{array}\right]$

Axiom 2 - Is known as "Information Axiom". On the basis of this axiom, when multiple alternative designs satisfying the first axiom are available, the information axiom must be used to choose the one with minimum information content. This can be accomplished by comparing the information content of the existing alternative solutions in terms of their probability of fulfilling the FRs. As a result, the best solution is the one that possesses the minimum information content and simultaneously satisfies Axiom 1 . The information content in a design which involves only one FR and one DP design is expressed as the logarithm of the inverse of the probability of the system/product/service success in satisfying the FR, P. This probability can be expressed as Equation 12;

$I=\log _{2} \frac{1}{P}$

In the simple case of a uniform probability distribution, the information content (I) can be defined as Equation 13, where; usually logarithms of base $2(\mathrm{x}=2)$ are used (Suh, 1990-2001; Malaek et al., 2015).

$I=\log _{X} \frac{(\text { Area of the system Range })}{(\text { Area of the common range })}$

Where; the area of the "System Range", SR, can be directly computed from FR's probability density function. The "SR" is the operating range of the designed system/product/ service. To be more specific, The "SR" of a given FR represents the actual "Performance Range", PR, associated with that FR.The SR is also known as the "Voice of the Process"(Yang and El-Haik, 2003). The area of the "Common Range", CR, is the fraction of the above mentioned area that is inside of the "Design Range", DR, as shown in Fig. 7. The DR defines the acceptable range associated with the specified DP. Actually, the DR is recognized as translation of the so called "Voice of the Customer" into technical domain with technical terms (Yang and El-Haik, 2003; El-Haik, 2005). 


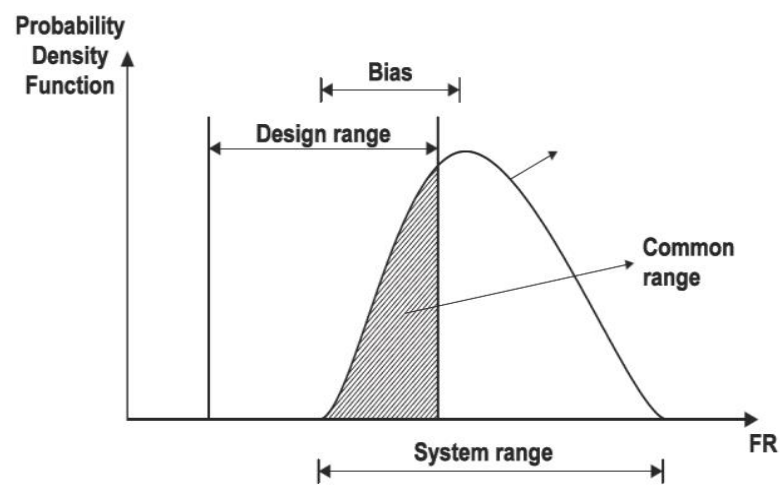

Fig. 7: Success Probability in Fulfilling A Single FR.

Therefore, for an uncoupled design of a product (system) which involves n FRs, the "Total Information Content", I, can be obtained via Equation 14.

$I=\sum_{i=1}^{n}-\log _{2} P_{i}=\sum_{i=1}^{n} I_{i}$

Where; $\mathrm{P}_{\mathrm{i}}$ is the probability of $\mathrm{FR}_{\mathrm{i}}$ being fulfilled by $\mathrm{DP} i$. As every probability, $\mathrm{P}_{\mathrm{i}}$, is equal to 1 , the information content is then zero. Conversely, the information content is infinite when one or more of the $\mathrm{P}_{\mathrm{i}}$ are equal to zero.

\subsection{Local linear neuro-fuzzy model}

Local linear modeling technique is based on dividing a complex modeling problem into a number of smaller and simpler sub-models such as linear models, which are identified independently and simply [14].

Local linear neuro-fuzzy model can be described with a network structure. In this network each neuron realizes a local linear model (LLM) and an associated validity function that determines the validity region of LLMs. The network structure of the local linear neuro-fuzzy model is depicted in Fig. 8. This model is a neuro-fuzzy model with linear neuron in the output layer that calculates LLM output from the input vector and a hidden layer which determines the weight of LLM output in final network output, according to Equation 15 and Equation 16 [14].

$\hat{y}_{i}=\sum_{i=1}^{M}\left(\omega_{i 0}+\omega_{i 1} \cdot u_{1}+\omega_{i 2} \cdot u_{2}+\cdots+\omega_{i p} \cdot u_{p}\right) \cdot \emptyset_{i}(U)$

$\emptyset_{i}=\frac{\mu_{i}(U)}{\sum_{j=1}^{M} \mu_{j}(U)}$

Where; $U=\left[u_{1}, u_{2}, \ldots, u_{p}\right]$ is the $\mathrm{p}$ dimensional input vector of the model, $\mathrm{W}_{\mathrm{ij}}$ is $\mathrm{j}^{\text {th }}$ LLM parameter of neuron $\mathrm{i}^{\text {th }}$, M is number of LLMs and $\emptyset_{i}$ is normalized Gaussian validity function of neuron $\mathrm{i}^{\text {th }}$ with $\mu_{i}(U)$ as expressed in Equation 17;

$\mu_{i}(U)=\exp \left(-\frac{1}{2}\left(\frac{\left(u_{1}-c_{i 1}\right)^{2}}{\sigma_{i 1}^{2}}+\cdots+\frac{\left(u_{p}-c_{i p}\right)^{2}}{\sigma_{i p}^{2}}\right)\right)$

$\exp \left(-\frac{1}{2} \cdot\left(\frac{\left(u_{1}-c_{i 1}\right)^{2}}{\sigma_{i 1}^{2}}\right) \times \ldots \times \exp \left(-\frac{1}{2} \cdot\left(\frac{\left(u_{p}-c_{i p}\right)^{2}}{\sigma_{i p}^{2}}\right)\right.\right.$

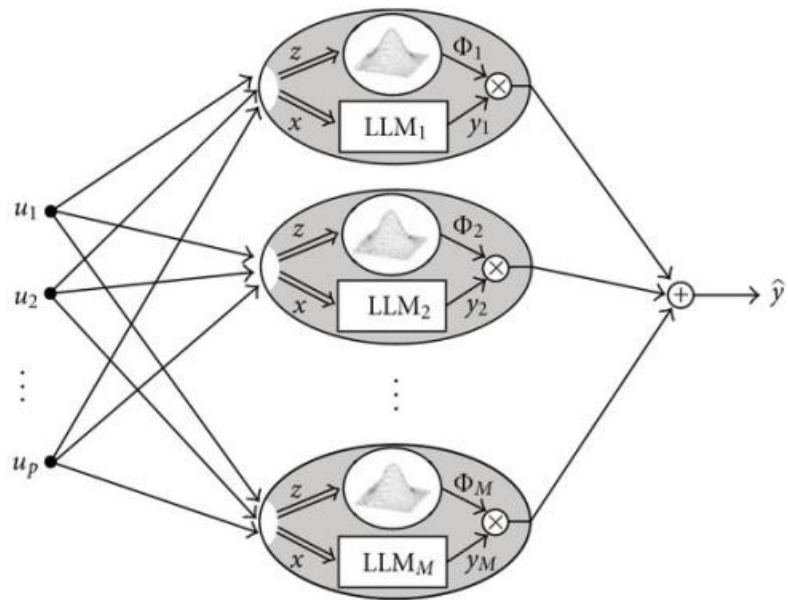

Fig. 8: Network Structure of Local Linear Neuro-Fuzzy Model with M Neuron Andp Input.

Each neuron of this network can be considered as a fuzzy rule in which the nonlinear parameters of Gaussian validity functions, center ( $\left.\mathrm{c}_{\mathrm{ij}}\right)$ and standard deviation $\left(\sigma_{i j}\right)$, are parameters of hidden layer and represent the rule premises and LLM parameters ( $\mathrm{W}_{\mathrm{ij}}$ ) represent the rule consequents. Optimization or learning methods are used to adjust these parameters [8]. 
Global optimization of $\mathrm{M}^{*}(\mathrm{P}+1)$ LLM parameters can be obtained by least square optimization technique. Assume that $\mathrm{W}$ is the parameter vector that contains all parameters

of LLMs as Equation 18;

$W=\left[w_{10}, w_{11}, \ldots, w_{1 p}, w_{20}, w_{21}, \ldots, w_{2 p}, \ldots, w_{M 0}, w_{M 1}, \ldots, w_{M p}\right]$

And $\mathrm{X}$ is the associated regression matrix for $\mathrm{N}$ measured data sample;

$X=\left[{ }_{\left.X_{1}^{S u b}, X_{2}^{S u b}, \ldots, X_{M}^{S u b}\right]}\right.$

Where;

$X_{i}^{S u b}=\left[\begin{array}{cccc}\emptyset_{i}(u(1)) & u_{1}(1) . \emptyset_{i}(u(1)) & . . & u_{p}(1) . \emptyset_{i}(u(1)) \\ \emptyset_{i}(u(2)) & u_{1}(2) . \emptyset_{i}(u(2)) & \ldots & u_{p}(2) . \emptyset_{i}(u(2)) \\ \ldots & \ldots & \ldots & \ldots \\ \emptyset_{i}(u(N)) & u_{1}(N) . \emptyset_{i}(u(N)) & \ldots & u_{p}(N) . \emptyset_{i}(u(N))\end{array}\right]$

Therefore, the model output can obtain from Equation 21;

$\hat{y}=X \cdot w$

So, LLM parameters can be obtained from Equation 22 [1]:

$\widehat{w}=\left(X^{T} \cdot X\right)^{-1} \cdot X^{T} \cdot Y$

Where; $\mathrm{y}$ is measured process output.

An incremental learning algorithm called local linear model tree algorithm, was applied in order to optimize the validity function parameters. For this purpose the input space is divided into smaller hypercubic subspaces and center of each hypercube is selected as center of LLM validity function. Standard deviation of LLM validity function is proportional to the hypercube extension. In each iteration the worst performing LLM is determined to be divided. All the possible divisions in the p dimensional input space are checked and the best is done. The LLM is divided into two equal halves on the selected input dimension and forms two independent LLMs with associated validity functions. The algorithm can be described in 4 steps :

1) Start with initial model: start with a single LLM. Construct the validity function for this LLM and estimate the LLM parameters of the model. Set $M$ to initial number of LLMs (M=l if no LLM is defined initially)

2) Find the worst LLM: calculate loss function e.g. NMES of all the LLMs and find the worst LLM based on the loss function

3) Check all divisions: the worst LLM is considered for further refinement. The hypercube of this LLM is split into two halves with an axis orthogonal spilt. Divisions in all dimensions are tried. For each division all these steps are carried out:

a) Construction of multidimensional validity functions for both new hypercubes.

b) Local estimation of the rule consequent parameters for both newly generated LLMs

c) Calculation of total loss function for current overall model

4) Select the best division: from $p$ alternative of divisions, the division which minimizes the overall loss function of the model is selected and its associated validity function, LLM is adopted for the model and the number of LLM is increased by $1(\mathrm{M}=\mathrm{M}+1)$.

5) Check for algorithm convergence: if the convergence criterion is satisfied the algorithm terminates otherwise continues from step2. Four iterations of local linear model tree (LoLiMoT) algorithm for two dimensional input space is depicted in Fig. 9.

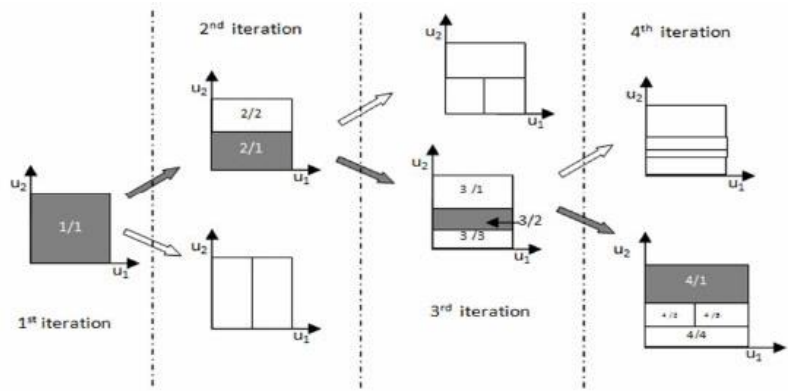

Fig. 9: Four Iteration of Local Linear Model Tree (Lolimot) Algorithm for Two Dimensional Input Space.

\subsection{Relevant works}

Wantland (1964) assumed Poisson's ratio for reservoir rocks and estimated shear wave velocities. However, Poisson's ratio is changing in a wide range in practice; hence the accuracy of estimated shear sonic data is questionable (Carroll, 1969). Another approach is to measure elastic properties of rocks through acoustic measurements of $\mathrm{Vp}$ and $\mathrm{Vs}$ using pulse transmission techniques in laboratory (Birch, 1960; Christensen, 1974; Kern, 1982; Burlini and Fountain, 1993; Ji and Salisbury, 1993; Watanabe et al., 2007). However, few lab data are available for Vs measurements compared to those of Vp (Ji et al., 2002). Pickett (1963), Castagna et al., (1985), Krief et al. (1990), Greenberg and Castagna (1992), Castagna et al. (1993), Bastos et al. (1998), Domenico (1984), Han (1989), Gassmann (1951) and Murphy et al. (1993) have introduced empirical relationships for Vs calculation. Carroll (1969) proposed the following empirical relation between compressional and shear wave velocities Castagna et al., 1993 proposed empirical equations for prediction of shear wave velocity in sandstone, limestone, shale and dolomite rocks. The use of a large range of empirical correlations has been reported during the last decades to 
estimate shear wave velocity from rock physical parameters (Castagna et al., 1993; Brocher, 2005, 2008; Ameen et al., 2009; Yasar and Erdogan, 2004). However, these correlations have been developed for a specific area and their use in other fields is subjected to uncertainties. In recent years, artificial intelligence (AI) methods have been used widely for prediction purposes (Feng, 1995; Mohammadi and Rahmannejad, 2009; Zhang et al., 2009). Once the network has been trained, it can make prediction, based on its previous learning, about the output related to new input data set of similar pattern. Support Vector Regression (SVR) is usually used as an efficient machine learning methodology for prediction of rock properties (Annan and Chunan, 2008; Kang and Wang, 2010; Niu and Li, 2010; Rechlin et al., 2011; Wenlin et al., 2011). The SVR relies on the statistical learning theory enabling learning machines to generalize the unseen data. This technique has proven to have superior performances in a variety of problems due to its generalization abilities and robustness against noise and interferences (Steinwart, 2008). SVM is a device for finding a solution which uses the minimum possible energy of the data (MartinezRamon and Cristodoulou, 2006; Cristianini and Shawe-Taylor, 2000). Brocher $(2005,2008)$ plotted thousands of wave velocity data for a wide range of lithologies from unconsolidated sediments to very low porosity igneous rocks, and from non-welded volcanic tuffs to highly compact metamorphic rocks to draw a non-linear equation Rezaee et al. (2006) used fuzzy logic, neuro-fuzzy and artificial neural network approaches as intelligent tools to predict Vs from conventional log data. The log data of two wells were used to construct intelligent models in a sandstone reservoir of the Carnarvon Basin, NW Shelf of Australia. A third well was used to evaluate the reliability of the models. The results showed that intelligent models were successful for prediction of Vs from conventional well log data. In the meanwhile, similar responses from different other intelligent methods indicated their validity for solving complex problems. Moatazedian et al. (2011) modeled Compressional and Shear Wave Velocities by Genetic Algorithms Technique in Ghar member of Asmari Formation, Hendijan Field. For measuring the accuracy of the method, predicted values were compared with the real data in Ghar member of Asmari Formation, Abuzar Field. Multiple Regression Analysis was used as alternative technique to evaluate the accuracy of the GA Model. The results of this study show that GA could be considered as an efficient, fast and cost-effective method for predicting Vs and Vp data from conventional well Log data. Predicted Compressional Wave Velocity along with Shear Wave Velocity, validates the reliability of Genetic Algorithms as an Optimization Technique for predicting parameters such as Vs. Maleki et al. (2014) used petrophysical logs corresponding to a well drilled in southern part of Iran to estimate the shear wave velocity using empirical correlations as well as two robust artificial intelligence methods knows as Support Vector Regression (SVR) and Back-Propagation Neural Network (BPNN). Although the results obtained by SVR seem to be reliable, the estimated values are not very precise and considering the importance of shear sonic data as the input into different models, this study suggests acquiring shear sonic data during well logging. It is important to note that the benefits of having reliable shear sonic data for estimation of rock formation mechanical properties will compensate the possible additional costs for acquiring a shear log.

\section{Methodology}

To describe the problem addressed by the current work and emphasize its relative importance in developing a relatively more efficient and effective approach to estimate the rocks porosity, at the first step, principles of "Linear Statistical Correlation Analysis" as well as "Statistical Analysis Methods to Examine the Distribution of Data" are actively used (Fig. 10). Next, as the second step, for each of the variables under consideration, if probability distribution of the data follows the normal probability distribution function, we can employ regular multiple linear regression analysis and continue. Otherwise, in order to estimate the relationship between input and output variables of the system, we have to go to the third step and utilize the "Fuzzy Regression Analysis" by finding the nature and magnitude of correlation between the concerned variables. Next, as the fourth step, in order to reach an effective predictor system which is capable of predicting value of interested response variables in a more robust and successful way, principles of Axiomatic Design (AD) theory, specially the first (independence) axiom, is employed. As the fifth step, integration of the LOcal LInear MOdel Tree (Lolimot) model, as a model from the neural network family, with Axiomatic Design (AD) theory to reach a more effective methodology for predicting the variables is proposed. As the sixth step, in order to verify capability of the proposed method integrating principles of the AD theory and Lolimot model, the existing predictor system used to estimate the rock porosity is addressed and actual data related to one of wells located in southern Iran is utilized. At this step, in order to examine ability of Axiomatic Design (AD) theory in reducing the complexity of the system and consider its contribution to improving simplicity and effectiveness of the predictor system, accuracy of the predictor system in predicting value of variables before and after applying the basic logic of Axiomatic Design (AD) theory to design the concerned predictor system is compared. For this aim, environments of software programming packages including SAS 8.2, GAMS 23.6, and MATLAB 2015 are effectively used to perform all mathematical and statistical analyses required to detect and accurately examine degree and nature of possible statistical dependency that might exist between any pair of the concerned variable. Eventually, at the seventh step, the final regression models describing the predictor system are confirmed and presented.

\section{Experiment: the case study}

In order to illustrate capability of the predictor system, proposed in this study, to estimate value of the main variables, the rock porosity related to one of wells located in southern Iran on the basis of real data is addressed. Indeed, in order to consider the role of Axiomatic Design (AD) theory, incorporated into local linear model Tree (lolimot), in improving effectiveness of the predictor system, accuracy of the improved system in estimating value of variables is compared with all other competing approaches.

In order to evaluate the ability of the system, "Root-Mean-Square Error (RMSE)", "Mean Absolute Percentage Error (MAPE)", and "Regression Coefficient Determination $\left(\mathrm{R}^{2}\right)$ " are all employed as three most important criteria providing useful information about the level of ability of the predictor system to estimate value of variables . 


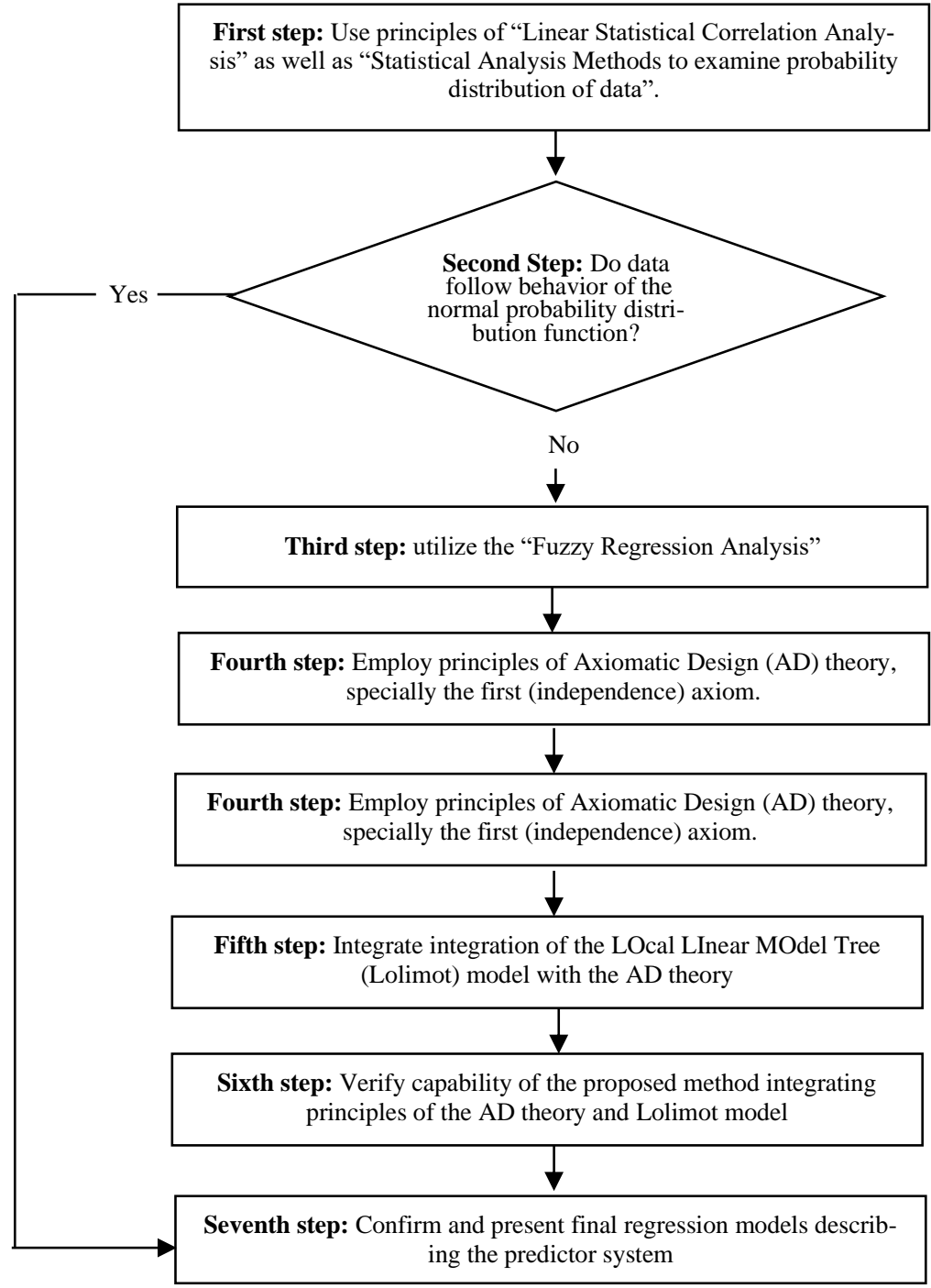

Fig. 10: Methodology of the Study in Algorithmic Display.

\subsection{Examination of data and data preparation}

Before performing any analysis, examination of the collected data and preparation of the data is helpful because the quality of the data can significantly affect results of the analysis and may lead to reaching invalid findings. For this reason, statistical examination of the data based on some statistical information including "basic statistical measures", "test for location $\left(\mathrm{H}_{0}: \mu_{0}=0\right.$ against $\left.\mathrm{H}_{1}: \mu_{1} \neq 0\right)$ ", "test for normality", and "test for correlation (association) between any pair of concerned variables" is to be carried out.

\subsubsection{Examination of distribution of the data based on basic statistical measures}

One of the most important sources which can provide useful information distribution of the data is "basic statistical measures". In this study, in order to examine distribution of the data, basic statistics related to location and variation of the data are considered. These information are presented in Table 1.

Table 1: Examination of Distribution of the Data based on Basic Statistical Measures

\begin{tabular}{|c|c|c|c|c|c|c|}
\hline & $\mathrm{X} 1$ & $\mathrm{X} 2$ & $\mathrm{X} 3$ & $\mathrm{X} 4$ & Y1 & $\mathrm{Y} 2$ \\
\hline $\mathrm{N}$ & 765 & 765 & 765 & 765 & 765 & 765 \\
\hline Mean & 28.5518831 & 2.41051399 & 1576.88147 & 3.65598045 & 20.2623791 & 1.8588237 \\
\hline Std Deviation & 15.2284263 & 0.25748942 & 7562.83006 & 0.81650696 & 8.56847501 & 0.43576801 \\
\hline Skewness & 0.84188356 & 0.56061247 & 4.80205728 & 1.01665994 & -0.9330641 & 0.87028232 \\
\hline Uncorrected SS & 800811.069 & 4495.74574 & 4.56003E10 & 10734.4839 & 370173.4 & 2788.32637 \\
\hline Coeff Variation & 53.3359788 & 10.6819303 & 479.606756 & 22.3334608 & 42.2876059 & 23.4432137 \\
\hline Sum Weights & 765 & 765 & 765 & 765 & 765 & 765 \\
\hline Sum Observations & 21842.1906 & 1844.0432 & 1206314.32 & 2796.82504 & 15500.72 & 1422.00013 \\
\hline Variance & 231.904968 & 0.0663008 & 57196398.5 & 0.66668361 & 73.418764 & 0.18989376 \\
\hline Kurtosis & 0.29127823 & -0.4113457 & 21.3197781 & -0.1697972 & -0.0284446 & -0.5261301 \\
\hline Corrected SS & 177175.396 & 50.6538139 & $4.3698 \mathrm{E} 10$ & 509.34628 & 56091.9357 & 145.078833 \\
\hline Std Error Mean & 0.55058492 & 0.00930955 & 273.434698 & 0.02952087 & 0.30979387 & 0.01575523 \\
\hline Median & 26.09790 & 2.371700 & 4.56 & 3.316345 & 23.01000 & 1.680865 \\
\hline Mode & 15.50150 & 2.162700 & 40000.00 & 5.379780 & 20.59000 & 2.034694 \\
\hline Range & 73.70290 & 1.44320 & 40000 & 3.09298 & 38.94000 & 1.67216 \\
\hline Interquartile Range & 20.09030 & 0.38160 & 13.70980 & 1.06328 & 10.03000 & 0.64011 \\
\hline
\end{tabular}


Where;

$\mathrm{X}_{1}$ : represents GR (api)

$\mathrm{X}_{2}$ : represents $\mathrm{RHOB}(\mathrm{g} / \mathrm{cc})$

$\mathrm{X}_{3}$ : represents LLD (ohm)

$\mathrm{X}_{4}$ : represents $\mathrm{Vp}(\mathrm{km} / \mathrm{s})$

$\mathrm{Y}_{1}$ : represents NPHI (\%)

$\mathrm{Y}_{2}$ : represents $\mathrm{Vs}(\mathrm{km} / \mathrm{s})$

In addition, in order to have a shape of distribution of the data, for each of the variables under consideration, histogram of the data is also displayed (Fig. 11);
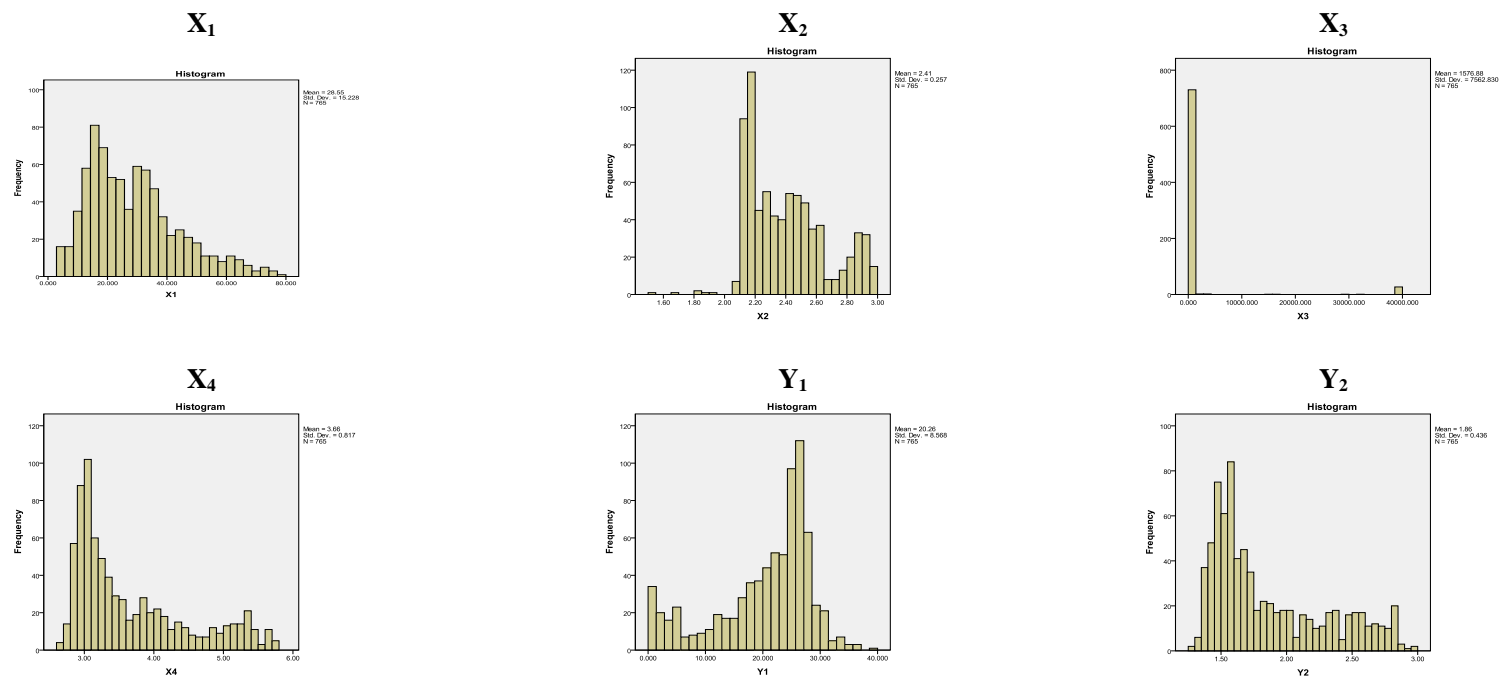

Fig. 11: Shape of Distribution of the Data, For Each of the Variables Under Consideration.

As can be seen in Fig. 11, with respect to each of the variables, any normal behavior cannot be reported. However, on the basis of the information provided in Table 1 , there is no considerably outlier observation that needs to be modified.

\subsubsection{Test for location $\left(\mathrm{H} 0: \mu_{0}=0\right.$ against $\left.\mathrm{H} 1: \mu_{1} \neq 0\right)$}

In order to examine the basic hypothesis, with respect to each variable $\left(\mathrm{X}_{1}-\mathrm{X}_{6}\right)$, mean of probability distribution of each variable using both parametric (T-student test) and non-parametric statistics (Signed and Signed Rank test) is tested. As can be seen in Table 2, there is a significant difference between value of mean of each variable and the zero value.

Table 2: Test for Location $\left(\mathrm{H}_{0}: \mathrm{M}_{0}=0\right.$ Against $\left.\mathrm{H}_{1}: \mathrm{M}_{1} \neq 0\right)$

\begin{tabular}{llllll}
\hline & Student's t & Sign & Signed Rank & $\operatorname{Pr}>|\mathrm{t}|$ & $\operatorname{Pr}>=|\mathrm{M}|$ \\
\hline $\mathrm{X}_{1}$ & 51.85737 & 382.5 & 146497.5 & $<.0001$ & $<.0001$ \\
$\mathrm{X}_{2}$ & 258.9292 & 382.5 & 146497.5 & $<.0001$ & $<.0001$ \\
$\mathrm{X}_{3}$ & 5.76694 & 382.5 & 146497.5 & $<.0001$ & $<.0001$ \\
$\mathrm{X}_{4}$ & 123.8439 & 382.5 & 146497.5 & $<.0001$ & $<.0001$ \\
$\mathrm{Y}_{1}$ & 65.406 & 382.5 & 146497.5 & $<.0001$ & $<.0001$ \\
$\mathrm{Y}_{2}$ & 117.9814 & 382.5 & 146497.5 & $<.0001$ & $<.0001$ \\
\hline
\end{tabular}

\subsubsection{Test for normality of data}

In order to employ any statistical analysis which is pillared on "normality" of distribution of the data, normality of the data must be checked. Table 3 shows the results of "Kolmogorov-Smirnov", "Cramer-von Mises", and "Anderson-Darling" test of data which belong to each of the concerned variables $\left(\mathrm{X}_{1}-\mathrm{Y}_{1}\right)$.

Table 3: Test for Normality of the Data

\begin{tabular}{|c|c|c|c|c|c|c|c|c|}
\hline & \multicolumn{2}{|l|}{ Shapiro-Wilk } & \multicolumn{2}{|c|}{ Kolmogorov-Smirnov } & \multicolumn{2}{|c|}{ Cramer-von Mises } & \multicolumn{2}{|c|}{ Anderson-Darling } \\
\hline & Statistic & Sig. & Statistic & Sig. & Statistic & Sig. & Statistic & Sig. \\
\hline $\mathrm{X}_{1}$ & 0.943559 & $<0.0001$ & 0.07922 & $<0.0100$ & 1.766739 & $<0.0050$ & 11.65704 & $<0.0050$ \\
\hline $\mathrm{X}_{2}$ & 0.926109 & $<0.0001$ & 0.102607 & $<0.0100$ & 2.518783 & $<0.0050$ & 18.4728 & $<0.0050$ \\
\hline $\mathrm{X}_{3}$ & 0.201313 & $<0.0001$ & 0.504067 & $<0.0100$ & 57.58026 & $<0.0050$ & 273.2672 & $<0.0050$ \\
\hline $\mathrm{X}_{4}$ & 0.854962 & $<0.0001$ & 0.168547 & $<0.0100$ & 6.888132 & $<0.0050$ & 40.67849 & $<0.0050$ \\
\hline $\mathrm{Y}_{1}$ & 0.89605 & $<0.0001$ & 0.135631 & $<0.0100$ & 5.143219 & $<0.0050$ & 30.38045 & $<0.0050$ \\
\hline $\mathrm{Y}_{2}$ & 0.872176 & $<0.0001$ & 0.168532 & $<0.0100$ & 6.49875 & $<0.0050$ & 37.12031 & $<0.0050$ \\
\hline
\end{tabular}

As can be clearly seen in Table 3, on the basis of all three test "Kolmogorov-Smirnov", "Cramer-von Mises", and "Anderson-Darling", the normality assumption for probability distribution of each variable is strongly rejected. In this regard, Fig. 12 and Fig. 13 also provide further information about violation of normality assumption in stochastic behavior of each of the variables $\mathrm{X}_{1}-\mathrm{Y}_{1}$. 


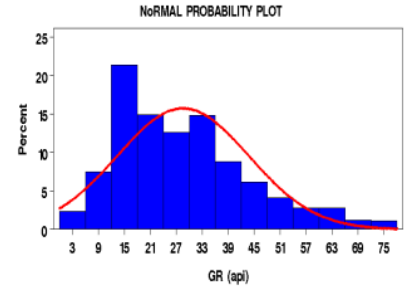

$\mathbf{X}_{4}$

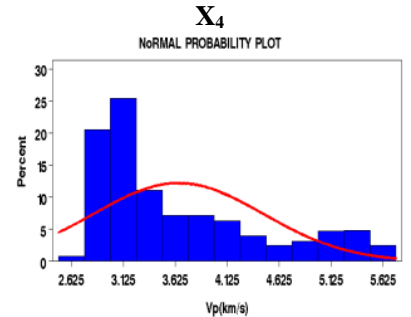

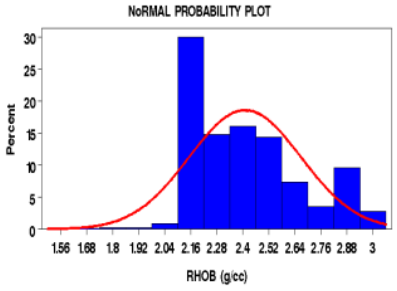

$\mathbf{Y}_{1}$

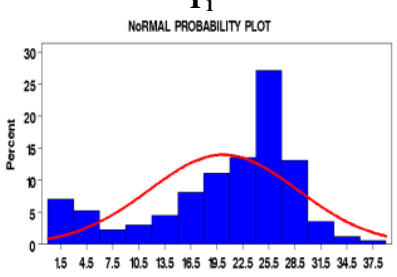

NPHI (8)

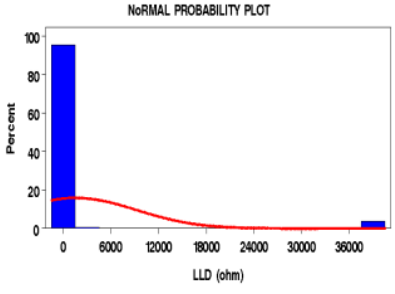

$\mathbf{Y}_{2}$

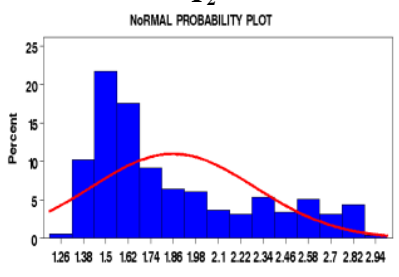

Vs(kmis)

Fig. 12: Distribution of Data Related to Each of Concerned Variables

With respect to Fig. 13, for each of the variables of interest, Q-Q Plot is displayed to compare distribution of data with normal distribution function;

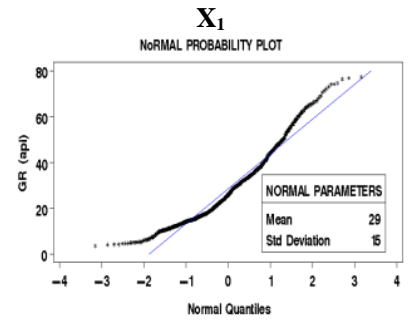

$\mathbf{X}_{4}$

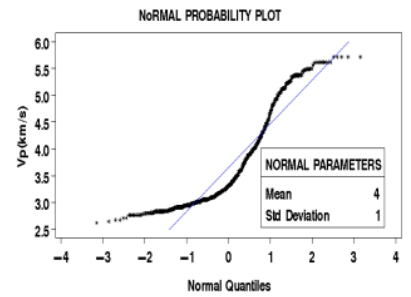

$\mathbf{X}_{2}$

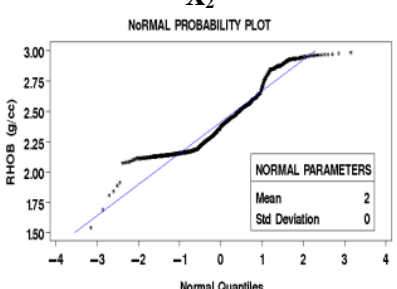

$\mathbf{Y}_{1}$

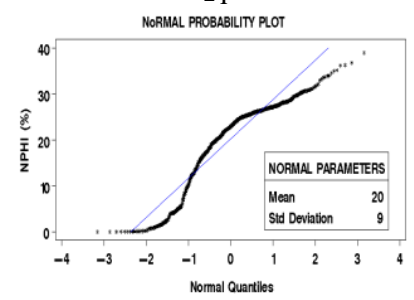

$\mathbf{X}_{3}$

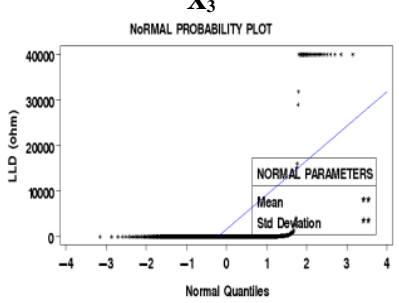

$\mathbf{Y}_{2}$

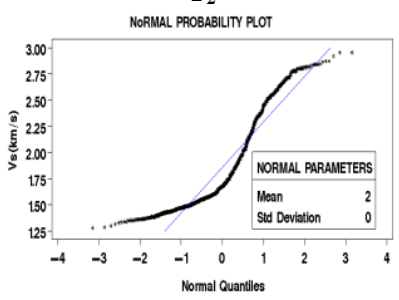

Fig. 13: Q-Q Plot to Compare Distribution of Data with Normal Distribution Function for each Concerned Variable.

\subsubsection{Test for correlation}

Measurement of degree of linear association between any pair of the concerned variables is another important step in data examination consideration. Moreover, information elicited from this step can somehow pave the way for developing some useful linear model describing nature and degree of association among the variables under study $\left(\mathrm{X}_{1}-\mathrm{Y}_{1}\right)$. For this purpose, scatter plot is employed to display shape of association between any pair of the variables (Fig. 14).

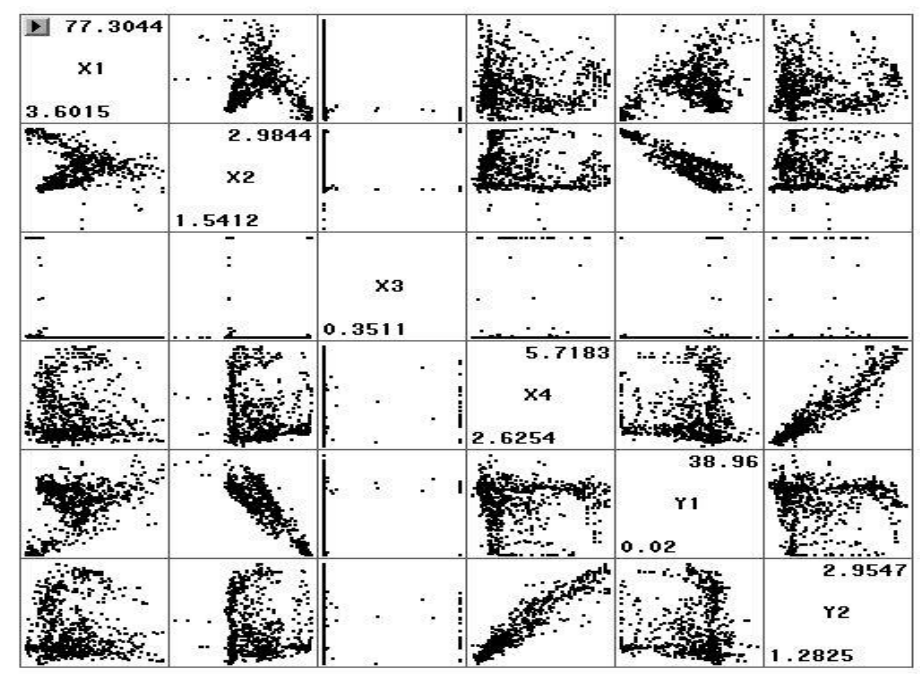

Fig. 14: Linear Correlation Between Any Pair of the Concerned Variables (X1, X2, X3, X4, Y1, Y2). 
As can be seen in Fig. 14, with respect to some of pairs of the variables, no linear correlation (association) can be found. For instance, in pair (X1, Y2), no linear relationship can be reported. However, despite of information provided by this Fig., in order to .... consider linear association between defined pairs of the variables under study, "Pearson Correlation Coefficients", "Spearman Correlation Coefficients", and "Kendall Tau b Correlation Coefficients" tests are employed to statistically test degree and significance of correlation between concerned variables. Table 4, Table 5, and Table 6 are to provide this information.

\begin{tabular}{|c|c|c|c|c|c|c|}
\hline & $\mathrm{X} 1$ & $\mathrm{X} 2$ & $\mathrm{X} 3$ & $\mathrm{X} 4$ & Y1 & $\mathrm{Y} 2$ \\
\hline $\mathrm{X} 1$ & \multirow{2}{*}{1.00000} & -0.05680 & -0.27126 & -0.03279 & 0.29702 & -0.03655 \\
\hline GR (api) & & 0.1165 & $<.0001$ & 0.3652 & $<.0001$ & 0.3126 \\
\hline $\mathrm{X} 2$ & -0.05680 & \multirow{2}{*}{1.00000} & 0.13241 & -0.14683 & -0.88640 & -0.15284 \\
\hline RHOB $(\mathrm{g} / \mathrm{cc})$ & 0.1165 & & 0.0002 & $<.0001$ & $<.0001$ & $<.0001$ \\
\hline $\mathrm{X} 3$ & -0.27126 & 0.13241 & \multirow{2}{*}{1.00000} & 0.01199 & -0.19415 & -0.01557 \\
\hline LLD (ohm) & $<.0001$ & 0.0002 & & 0.7405 & $<.0001$ & 0.6673 \\
\hline $\mathrm{X} 4$ & -0.03279 & -0.14683 & 0.01199 & \multirow{2}{*}{1.00000} & 0.05243 & 0.95065 \\
\hline $\mathrm{Vp}(\mathrm{km} / \mathrm{s})$ & 0.3652 & $<.0001$ & 0.7405 & & 0.1474 & $<.0001$ \\
\hline Y1 & 0.29702 & -0.88640 & -0.19415 & 0.05243 & \multirow{2}{*}{1.00000} & 0.05798 \\
\hline NPHI (\%) & $<.0001$ & $<.0001$ & $<.0001$ & 0.1474 & & 0.1091 \\
\hline $\mathrm{Y} 2$ & -0.03655 & -0.15284 & -0.01557 & 0.95065 & 0.05798 & \multirow{2}{*}{1.00000} \\
\hline $\mathrm{Vs}(\mathrm{km} / \mathrm{s})$ & 0.3126 & $<.0001$ & 0.6673 & $<.0001$ & 0.1091 & \\
\hline
\end{tabular}

As can be seen, on the basis of the P-value reported for every pair of the variables, correlation between some pairs of variable is not significant and, hence, the assumption of linear association between these pairs of the variables is rejected. In this regard, information presented in Table 5 and Table 6 also confirm results obtained from the above.

Table 5: Spearman Correlation Coefficients, $N=765$, Prob $>|R|$ Under H0: Rho $=0$

\begin{tabular}{|c|c|c|c|c|c|c|}
\hline & $\mathrm{X} 1$ & $\mathrm{X} 2$ & $\mathrm{X} 3$ & $\mathrm{X} 4$ & Y1 & $\mathrm{Y} 2$ \\
\hline $\mathrm{X} 1$ & 1.00000 & 0.14085 & -0.72963 & -0.02167 & 0.12279 & -0.01835 \\
\hline GR (api) & & $<.0001$ & $<.0001$ & 0.5496 & 0.0007 & 0.6123 \\
\hline $\mathrm{X} 2$ & 0.14085 & 1.00000 & 0.04802 & -0.07777 & -0.80585 & -0.11749 \\
\hline RHOB (g/cc) & $<.0001$ & & 0.1846 & 0.0315 & $<.0001$ & 0.0011 \\
\hline $\mathrm{X} 3$ & -0.72963 & 0.04802 & 1.00000 & -0.00918 & -0.16194 & -0.04446 \\
\hline LLD (ohm) & $<.0001$ & 0.1846 & & 0.7999 & $<.0001$ & 0.2193 \\
\hline $\mathrm{X} 4$ & -0.02167 & -0.07777 & -0.00918 & 1.00000 & -0.04779 & 0.93821 \\
\hline $\mathrm{Vp}(\mathrm{km} / \mathrm{s})$ & 0.5496 & 0.0315 & 0.7999 & & 0.1867 & $<.0001$ \\
\hline $\mathrm{Y} 1$ & 0.12279 & -0.80585 & -0.16194 & -0.04779 & 1.00000 & -0.01323 \\
\hline NPHI (\%) & 0.0007 & $<.0001$ & $<.0001$ & 0.1867 & & 0.7149 \\
\hline $\mathrm{Y} 2$ & -0.01835 & -0.11749 & -0.04446 & 0.93821 & -0.01323 & 1.00000 \\
\hline $\mathrm{Vs}(\mathrm{km} / \mathrm{s})$ & 0.6123 & 0.0011 & 0.2193 & $<.0001$ & 0.7149 & \\
\hline
\end{tabular}

Table 6: Kendall Tau B Correlation Coefficients, $N=765$, Prob $>|R|$ Under H0: Rho=0

\begin{tabular}{|c|c|c|c|c|c|c|}
\hline & $\mathrm{X} 1$ & $\mathrm{X} 2$ & X3 & $\mathrm{X} 4$ & Y1 & Y2 \\
\hline $\mathrm{X} 1$ & 1.00000 & 0.12196 & -0.53934 & -0.01478 & 0.08066 & -0.01333 \\
\hline GR (api) & & $<.0001$ & $<.0001$ & 0.5412 & 0.0008 & 0.5811 \\
\hline $\mathrm{X} 2$ & 0.12196 & 1.00000 & 0.05230 & -0.04677 & -0.63426 & -0.07101 \\
\hline RHOB (g/cc) & $<.0001$ & & 0.0305 & 0.0531 & $<.0001$ & 0.0033 \\
\hline $\mathrm{X} 3$ & -0.53934 & 0.05230 & 1.00000 & -0.00460 & -0.12783 & -0.03153 \\
\hline LLD (ohm) & $<.0001$ & 0.0305 & & 0.8492 & $<.0001$ & 0.1923 \\
\hline $\mathrm{X} 4$ & -0.01478 & -0.04677 & -0.00460 & 1.00000 & -0.03233 & 0.78630 \\
\hline $\mathrm{Vp}(\mathrm{km} / \mathrm{s})$ & 0.5412 & 0.0531 & 0.8492 & & 0.1814 & $<.0001$ \\
\hline Y1 & 0.08066 & -0.63426 & -0.12783 & -0.03233 & 1.00000 & -0.00995 \\
\hline NPHI (\%) & 0.0008 & $<.0001$ & $<.0001$ & 0.1814 & & 0.6807 \\
\hline Y2 & 1.00000 & 0.12196 & -0.53934 & -0.01478 & 0.08066 & -0.01333 \\
\hline $\mathrm{Vs}(\mathrm{km} / \mathrm{s})$ & & $<.0001$ & $<.0001$ & 0.5412 & 0.0008 & 0.5811 \\
\hline
\end{tabular}

\subsection{Fuzzy regression analysis}

With reference to the results obtained from normality test of probability distribution for each of the variables, the classical simple/ multiple linear regression models cannot be used to describe and explain the relationship among the variables under study. For this reason, in this study, in order to explain the relationship among variables of interest as a simple/multiple linear regression model, "Fuzzy Regression Analysis" is utilized. In fact, the fuzzy linear regression is applied to find an interrelationship between the linear interval model and the output intervals of the given data forecasting in an uncertain environment. For this purpose, the Tanaka's model is employed so as to develop the linear function describing the relationship between the concerned variables.

Regarding developing the fuzzy regression model intended to explain and predict uncertain behavior of response variables, two variables $\mathrm{Y}_{1}(\mathrm{NPHI})$ and $\mathrm{Y}_{2}(\mathrm{Vs})$ are considered to be the dependent (response) variables. However, on the other side, to explain the behavior of these two dependent variables, four variables $\mathrm{X}_{1}-\mathrm{X}_{4}$ are regarded as independent (explanatory) variables. However, prior to developing the fuzzy regression model which is intended to explain the behavior of the response variable of interest, knowledge about association between the variables under consideration is useful. In other words, in order to find a set of sound explanatory (independent) variables to estimate behavior of the dependent variables, results of analysis of correlations between variables can be usefully utilized.

With respect to modeling uncertain behavior of response variable $Y_{1}$, benefiting from results of analyses of statistical correlation between variables, the variable $\mathrm{X}_{2}$ is only chosen as the most appropriate independent variable. On the basis of this decision, the fuzzy regression model, developed based on modified Tanaka's approach, can be expressed as follows;

The scatter plot and fuzzy regression line explaining uncertainty in response variable Y1 is given in Fig. 15; 


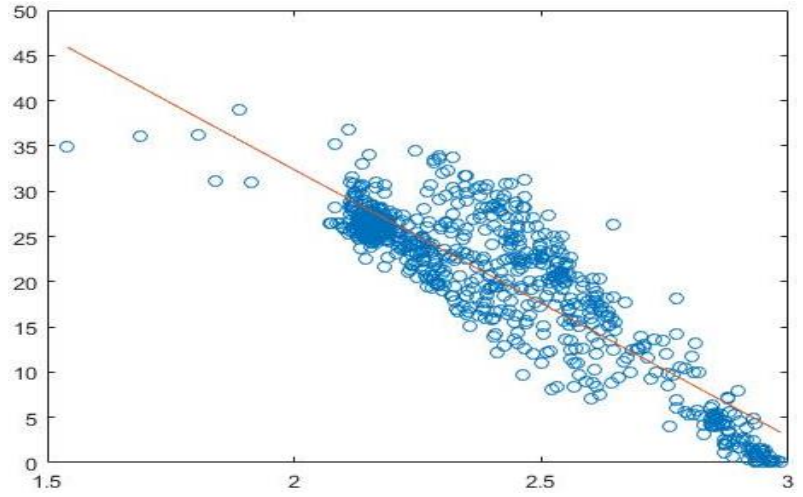

Fig. 15: Plot of Fuzzy Linear Regression Analysis to Predict $Y_{1}$

In addition, the linear fuzzy regression model, resulted from solving the related linear programming model, can be expressed as Equation 23 and Equation 24;

$\mathrm{i}_{1}=6.805+(18.839) \cdot \mathrm{x}_{2}$

$\mathrm{i}_{2}=28.966+(18.839) \cdot \mathrm{x}_{2}$

Following developing the linear fuzzy regression model linking the independent variable $X_{2}$ to dependent variable $Y_{1}$, learning about accuracy (capability) of the model to estimate dependent variable $Y_{1}$ is interested. For the purpose of evaluating capability of the model, Root-Mean-Square Error (RMSE), Mean Absolute Percentage Error (MAPE), and ( $\mathrm{R}^{2}$ ) are used as important criteria. As can be seen in Table 7, 96\% of all variations of the dependent variable $\mathrm{Y}_{1}$ can be explained by the fuzzy regression liner models expressed in Equation 23 and Equation 24.

Table 7: Evaluation of Fuzzy Regression Analysis

\begin{tabular}{|c|c|c|c|}
\hline Criteria & RMSE & MAPE & $\mathrm{R}^{2}$ \\
\hline Fuzzy Regression Analysis & 3.9640 & 15.5931 & 0.9675 \\
\hline
\end{tabular}

Moreover, with respect to modeling uncertain behavior of response variable $\mathrm{Y}_{2}$, benefiting from results of analyses of statistical correlation between variables, the variable $\mathrm{X}_{4}$ is only chosen as the most appropriate independent variable. On the basis of this decision, the fuzzy regression model, developed based on modified Tanaka's approach, can be expressed as follows;

The scatter plot and fuzzy regression line explaining uncertainty in response variable $\mathrm{Y}_{2}$ is given in Fig. 16;

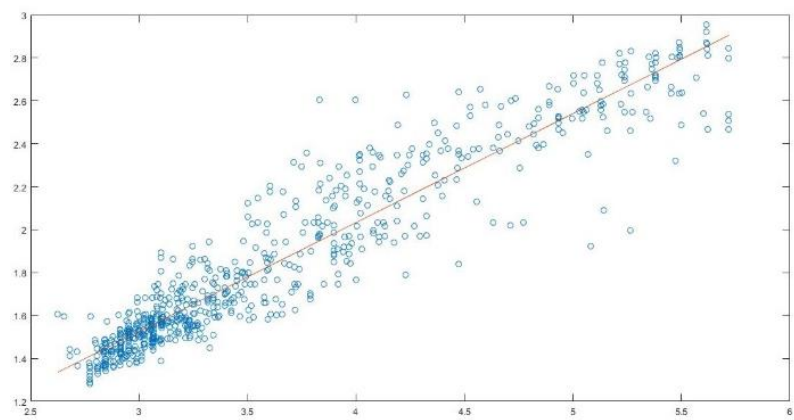

Fig. 16: Plot of Fuzzy Linear Regression Analysis to Predict $Y_{2}$

In addition, the linear fuzzy regression models, resulted from solving the related linear programming model, can be expressed as Equation 25 and Equation 26;

$$
\begin{aligned}
& \mathrm{i}_{1}=2.715+(1.839) \cdot \mathrm{x}_{4} \\
& \mathrm{i}_{2}=3.965+(1.839) \cdot \mathrm{x}_{4}
\end{aligned}
$$

Furthermore, following developing the linear fuzzy regression model linking the independent variable $\mathrm{X}_{4}$ to dependent variable $\mathrm{Y}_{2}$, learning about accuracy (capability) of the model to estimate dependent variable $\mathrm{Y}_{2}$ is interested. For the purpose of evaluating capability of the model, Root-Mean-Square Error (RMSE), Mean Absolute Percentage Error (MAPE), and $\left(\mathrm{R}^{2}\right)$ are used as important criteria. As can be seen in Table $8, \ldots \%$ of all variations of the dependent variable $\mathrm{Y}_{1}$ can be explained by the fuzzy regression liner models expressed in Equation 25 and Equation 26.

\begin{tabular}{|c|c|c|c|}
\hline Criteria & RMSE & MAPE & $\mathrm{R}^{2}$ \\
\hline Fuzzy Regression Analysis & 0.1351 & 0.9950 & 5.1674 \\
\hline
\end{tabular}

Table 8: Evaluation of Fuzzy Regression Analysis

\subsection{Local linear model tree (Lolimot) and axiomatic design (AD) theory}


Local Linear Model Tree (Lolimot), as a model from the neural network family, can be utilized as one of the most useful approaches to estimate values of the response variables. Regarding this approach, determination of number of neurons that are required to more precisely estimate the response variables is critical.

As can be seen in Fig. 17 and Fig. 18, concerning the response variable $\mathrm{Y}_{1}$ (NPHI), one the basis of root mean square error criterion, the sound number of neurons required to more effectively estimate values of the response variable $\mathrm{Y}_{1}$ is determined to be two neurons.

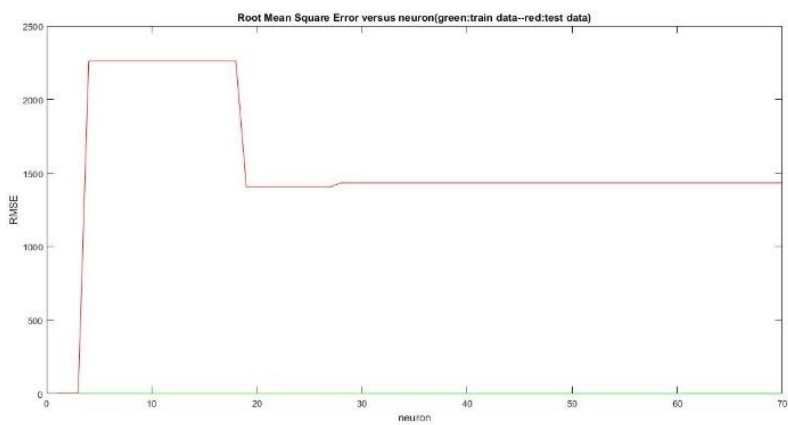

Fig. 17: Plot to Identify Required Number of Neurons to Estimate Values of the Response Variable $Y_{1}$ by Lolimot Approach.

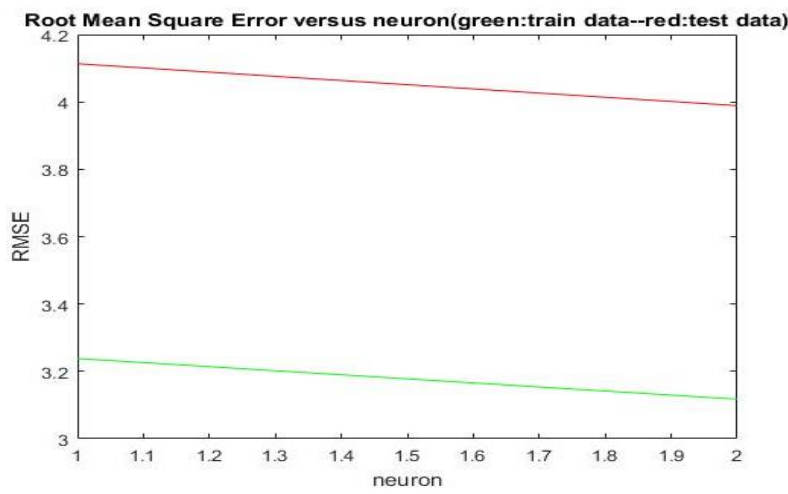

Fig. 18: Root Mean Square Error in a Lolimot Model with Two Neurons $\left(\mathrm{Y}_{1}\right)$

However, to reach an effective predictor system which is capable of predicting value of the response variable $\mathrm{Y}_{1}$ (NPHI) in a more robust and successful way, principles of Axiomatic Design (AD) theory, specially the first (independence) axiom, is employed. Indeed, here result of integration of the Lolimot model with the Axiomatic Design (AD) theory so as to achieve a more effective tool for predicting the values of the response variable $\mathrm{Y}_{1}$ (NPHI) is concerned. For this aim, try to identify proper number of neurons required to estimate values of the response variable $\mathrm{Y}_{1}$ by Lolimot approach where the first (independence) axiom of the AD theory is integrated into the original Lolimot model is continued (Fig. 19 and Fig. 20).

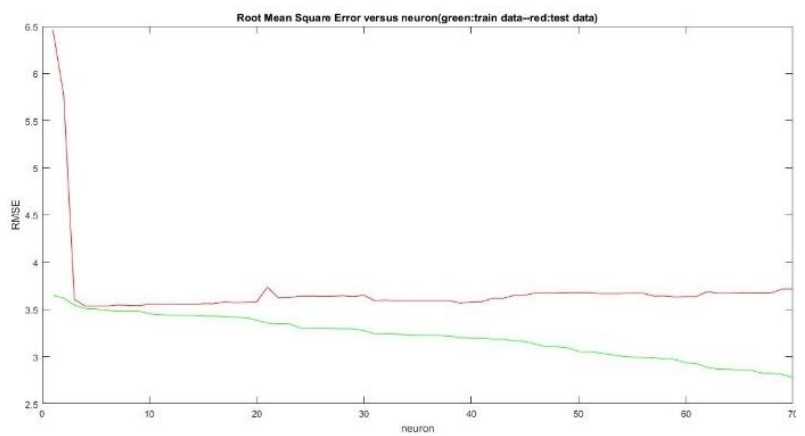

Fig. 19: Plot to Identify Required Number of Neurons to Estimate Values of the Response Variable $Y_{1}$ Where AD Theory Is Integrated into the Original Lolimot Model.

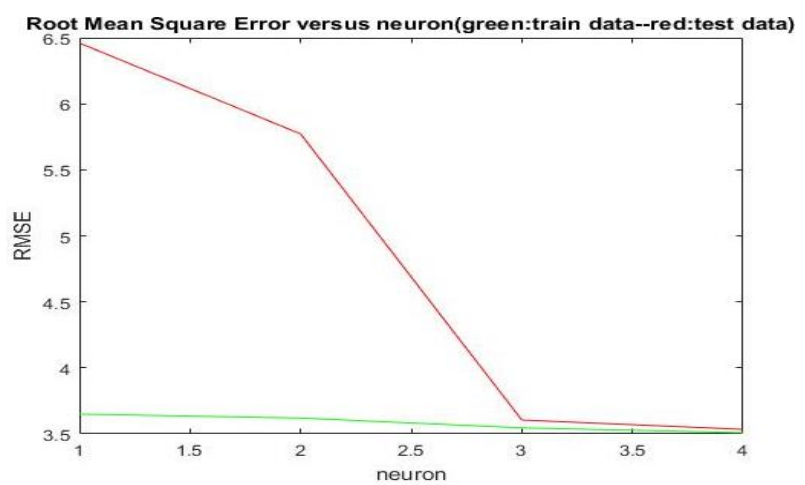

Fig. 20: Root Mean Square Error in a Lolimot Model with Two Neurons where the AD theory is integrated $\left(\mathrm{Y}_{1}\right)$. 
Comparing three critical criteria RMSE, MAPE, and $\mathrm{R}^{2}$, relative strength of the predictor system in estimating and/or predicting value of the response variable $Y_{1}$ can be clarified. According to Table 9, the superiority of the predictor system which has been established based on LOLIMOT technique integrated with the Axiomatic Design (AD) theory comparing with the system which has been pillared upon only the LOLIMOT technique can be concluded.

Table 9: Comparison of LOLIMOT Technique Without Axiomatic Design Approach and LOLIMOT Technique with Axiomatic Design Approach

\begin{tabular}{|c|c|c|c|}
\hline Criteria & RMSE & MAPE & $\mathrm{R}^{2}$ \\
\hline Approach & & & \\
\hline $\begin{array}{l}\text { LOLIMOT Technique Without Axiomatic Design Approach } \\
\text { LOLIMOT Technique with Axiomatic Design Approach }\end{array}$ & $\begin{array}{l}3.9889 \\
3.5343\end{array}$ & $\begin{array}{l}32.0537 \\
31.2825\end{array}$ & $\begin{array}{l}0.8266 \\
0.8638\end{array}$ \\
\hline
\end{tabular}

Similarly, concerning the response variable $\mathrm{Y}_{2}(\mathrm{Vs})$, as can be seen in Fig. 21 and Fig. 22, one the basis of root mean square error criterion, the sound number of neurons required to more effectively estimate values of the response variable $\mathrm{Y}_{2}$ is determined to be two neurons.

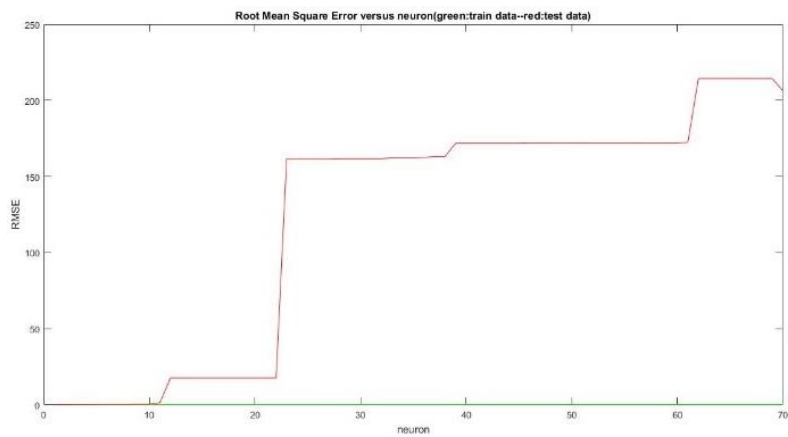

Fig. 21: Plot to Identify Required Number of Neurons to Estimate Values of the Response Variable $Y_{2}$ by Lolimot Approach.

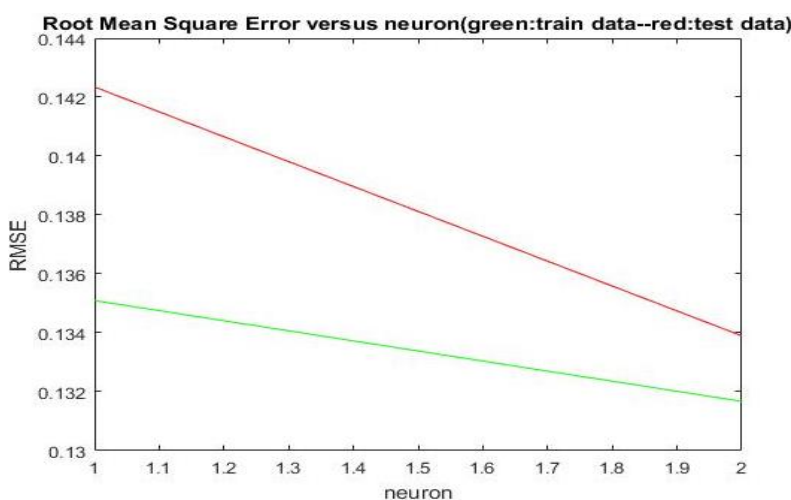

Fig. 22: Root Mean Square Error in a Lolimot Model with Two Neurons $\left(\mathrm{Y}_{2}\right)$

However, to reach an effective predictor system which is capable of predicting value of the response variable $\mathrm{Y}_{2}$ (Vs) in a more robust and successful way, principles of Axiomatic Design (AD) theory, specially the first (independence) axiom, is employed. Indeed, here result of integration of the Lolimot model with the Axiomatic Design (AD) theory so as to achieve a more effective tool for predicting the values of the response variable $\mathrm{Y}_{2}(\mathrm{Vs})$ is concerned. For this aim, try to identify proper number of neurons required to estimate values of the response variable $\mathrm{Y}_{2}$ by Lolimot approach where the first (independence) axiom of the AD theory is integrated into the original Lolimot model is continued (Fig. 23 and Fig. 24).

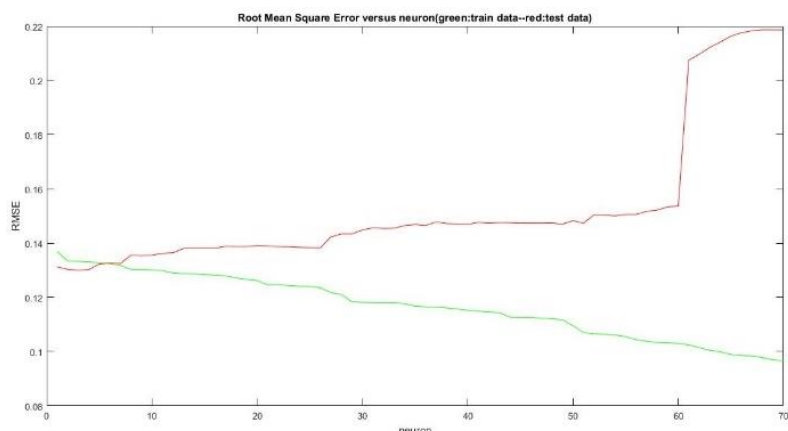

Fig. 23: Plot to Identify Required Number of Neurons to Estimate Values of the Response Variable $Y_{2}$ Where AD Theory Is Integrated Into the Original Lolimot Model. 


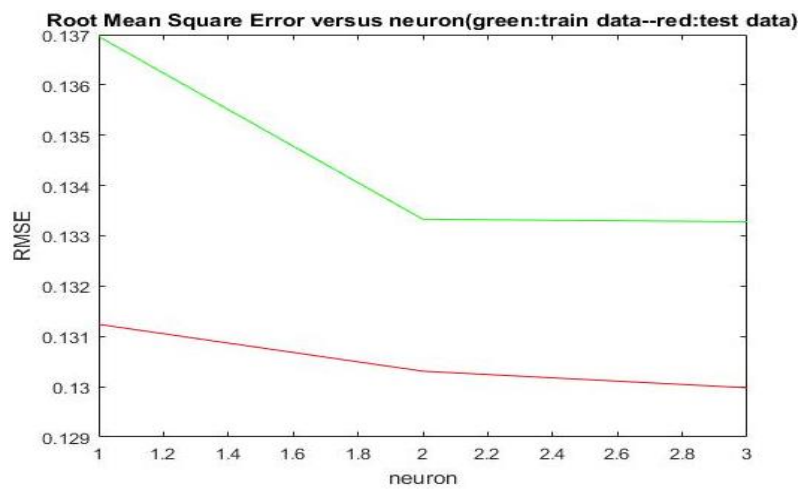

Fig. 24: Root Mean Square Error in a Lolimot Model with Two Neurons where the AD theory is integrated $\left(\mathrm{Y}_{2}\right)$.

Similarly, regarding the dependent variable $\mathrm{Y}_{2}$, comparing three critical criteria RMSE, MAPE, and $\mathrm{R}^{2}$, relative strength of the predictor system in estimating and/or predicting value of the response variable $\mathrm{Y}_{2}$ can also be clarified. According to Table 10, the superiority of the predictor system which has been established based on LOLIMOT technique integrated with the Axiomatic Design (AD) theory comparing with the system which has been pillared upon only the LOLIMOT technique can be concluded as well.

Table 10: Comparison of LOLIMOT Technique Without Axiomatic Design Approach and LOLIMOT Technique with Axiomatic Design Approach

\begin{tabular}{|c|c|c|c|}
\hline Criteria & RMSE & MAPE & $\mathrm{R}^{2}$ \\
\hline Approach & & & \\
\hline $\begin{array}{l}\text { LOLIMOT Technique Without Axiomatic Design Approach } \\
\text { LOLIMOT Technique with Axiomatic Design Approach }\end{array}$ & $\begin{array}{l}0.1339 \\
0.13\end{array}$ & $\begin{array}{l}4.7531 \\
4.6267\end{array}$ & $\begin{array}{l}0.9274 \\
0.9316\end{array}$ \\
\hline
\end{tabular}

\section{Conclusion}

Shear and Compressional Wave Velocities along with other Petrophysical Logs, are considered as upmost important data for Hydrocarbon reservoirs characterization. Shear Wave Velocity (Vs) in Well Logging is commonly measured by some sort of Dipole Logging Tools, which are able to acquire Shear Waves as well as Compressional Waves such as Sonic Scanner, DSI (Dipole Shear Sonic imager) by Schlumberger and MDA (Monopole-Dipole Array) by Weatherford Company. Usually in Old Wells, there is lack of Shear Velocity data, or in other Wells, only some intervals may have Vs data. Shear Wave Velocity is of high importance in Geophysical studies such as AVO (Amplitude Variation with Offset) and VSP (Vertical Seismic Profiling) and along with Compressional Wave Velocity, it can be used for identification of Fluid Type, Lithology and Mechanical Rock Properties. In this study, porosity of the extracted rocks form concerned wells is interest as it can indicate the oil capacity of the wells of interest. In this study, we actively use the principles of "Linear Statistical Correlation Analysis" and "Statistical Analysis Methods to Examine the Distribution of Data", and "Fuzzy Regression Analysis" to find the nature and magnitude of correlation between input variables and output of the system. Next, we employ the principles of Axiomatic Design theory, specially the first (independence) axiom, to reduce the system more simple and make the measurement system simpler .As the next step, for the purpose of clarifying the strength of Axiomatic Design theory in reducing the complexity of the system and optimizing the measurement system, we utilize the The Lolimot model (LOcal LInear MOdel Tree) as a model from the neural network family and apply it before and after implementing the basic logic of Axiomatic Design (AD) theory. In addition, in order to illustrate strength of the proposed method emphasizing the effectiveness of a method which benefit from both AD theory and Lolimot model together, the existing system used to measure the rock porosity is addressed and actual data related to one of wells located in southern Iran is utilized. The results of the study show that integrating the Axiomatic Design principles with the LOLIMOT method leads to the least complex and most accurate results.

\section{References}

[1] Ameen, M.S., Smart, B.G.D., Somerville, J.M., Hammilton, S., Naji, N.A., 2009. Predicting rock mechanical properties of carbonates from wireline logs. Mar. Pet. Geol. 26, 430-444. https://doi.org/10.1016/j.marpetgeo.2009.01.017.

[2] Annan, J., Chunan, T., 2008. Forecasting peak acceleration of blasting vibration of rock mass based on PSO-SVM, Control and Decision Conference, CCDC, $2541-2545$.

[3] Archer N.P. and Wang S. (1993). Application of the backpropagation neural network algorithm with montonicity constraints for two-group classification problems. Decision Sciences, 24(1), 60-75. https://doi.org/10.1111/j.1540-5915.1993.tb00462.x.

[4] Bandyopadhyay, S., Pal, S.K., 2007. Classification and Learning Using Genetic Algorithms. Springer, pp. 320.

[5] Bhattacharyya S. and Pendharkar P.C. (1998). Inductive, evolutionary, and neural computing techniques for discrimination: a comparative study. Decision Sciences29(4), 871-899. https://doi.org/10.1111/j.1540-5915.1998.tb00880.x.

[6] Birch, F., 1960. The velocity of compressional waves in rocks 10 kbars: Part 1. J. Geophys. Res. 65, 83-1102. https://doi.org/10.1029/JZ065i004p01083.

[7] Boonen, P., Bean, C., Tepper, R., Deady, R., 1998. Important implications from a comparison of LWD and wireline acoustic data from a Gulf of Mexico well. In: Transition of 39th SPWLA Annual Logging Symposium, Keystone, CO.

[8] Brocher, T.M., 2005. Empirical relations between elastic wavespeeds and density in the earth's crust. Bull. Seismol. Soc. Am. 95, $2081-2092$. https://doi.org/10.1785/0120050077.

[9] Brocher, T.M., 2005. Empirical relations between elastic wavespeeds and density in the earth's crust. Bull. Seismol. Soc. Am. 95, $2081-2092$. https://doi.org/10.1785/0120050077.

[10] Brocher, T.M., 2008. Key elements of regional seismic velocity models for long period ground motion simulations. J. Seismol. 12 (2), $217-221$. https://doi.org/10.1007/s10950-007-9061-3. 
[11] Brocher, T.M., 2008. Key elements of regional seismic velocity models for long period ground motion simulations. J. Seismol. 12 (2), $217-221$. https://doi.org/10.1007/s10950-007-9061-3.

[12] Burke L. (1991). Introduction to artificial neural systems for pattern recognition. Computers and Operations Research, 18(2), 211-220. https://doi.org/10.1016/0305-0548(91)90091-5.

[13] Burlini, L., Fountain, D.M., 1993. Seismic anisotropy of metapelites from the Ivrea-Verbano zone and Serie dei Laghi (northern Italy). Phys. Earth Planet 78, 301-317. https://doi.org/10.1016/0031-9201(93)90162-3.

[14] Carroll, R.D., 1969. The determination of acoustic parameters of volcanic rocks from compressional velocity measurements. Int. J. Rock Mech. Min Sci. 6, 557-579. https://doi.org/10.1016/0148-9062(69)90022-9.

[15] Carroll, R.D., 1969. The determination of acoustic parameters of volcanic rocks from compressional velocity https://doi.org/10.1016/01489062(69)90022-9.

[16] Castagna, J.P., Batzle, M.L., Kan, T.K. 1993. Rock physics-The link between rock properties and AVO response. In: Castagna, J.P., and Backus, M., (Eds.), Offset-dependent reflectivity-Theory and practice of AVO analysis: Investigations in Geophysics, vol. 8, pp. 135-171. https://doi.org/10.1190/1.9781560802624.

[17] Castagna, J.P., Batzle, M.L., Kan, T.K. 1993. Rock physics-The link between rock properties and AVO response. In: Castagna, J.P., and Backus, M., (Eds.), Offset-dependent reflectivity-Theory and practice of AVO analysis: Investigations in Geophysics, vol. 8, pp. 135-171. https://doi.org/10.1190/1.9781560802624.

[18] Christensen, N.I., 1974. Compressional wave velocities in possible mantle rocks to pressures of 30 kilobars. J. Geophys. Res. 79, 407-412. https://doi.org/10.1029/JB079i002p00407.

[19] Christensen, N.I., 1974. Compressional wave velocities in possible mantle rocks to pressures of 30 kilobars. J. Geophys. Res. 79, 407-412. https://doi.org/10.1029/JB079i002p00407.

[20] D.S. Savic D.S. and W. Pedrycz W. (1991). Evaluation of fuzzy linear regression models. Fuzzy Sets and Systems, 39, 51-63. https://doi.org/10.1016/0165-0114(91)90065-X.

[21] Eberhart R.C. and Dobbins R.W. (1990). Neural Network PC Tools: A Practical Guide. Academic Press.

[22] Eissa, A., Kazi, A., 1988. Relation between static and dynamic Young's moduli of rocks. Int. J. RockMech. Min. Sci. 25 (6), 479-482. https://doi.org/10.1016/0148-9062(88)90987-4.

[23] El-Haik, B. S., and Yang, K., The components of complexity in engineering design, IIE Transactions, 1999, Vol. 31, No. 10, pp. 92 https://doi.org/10.1080/07408179908969893.

[24] EL-HAIK, B. S., Axiomatic Quality: Integrating Axiomatic Design with Six-Sigma, Reliability, and Quality Engineering, New Jersey: John Wiley \& Sons, 2005. https://doi.org/10.1002/0471714682.

[25] Feng, X., 1995. A neural network approach to comprehensive classification of rock stability, blastability and drillability. Int. J. Min, Reclama. EnviroN 9 (2), 57-62. https://doi.org/10.1080/09208119508964719.

[26] H. Tanaka H., S. Uejima S., and K Asai K. (1982). Linear regression analysis with fuzzy model. IEEE Transactions on Systems, Man, and Cybernetics, 12, 903-907. https://doi.org/10.1109/TSMC.1982.4308925.

[27] Han I., Chandler J.S., and Liang T.P. (1996). The impact of measurement scale and correlation structure on classification performance of inductive learning and statistical methods. Expert Systems with Applications, 10(2), 209-221. https://doi.org/10.1016/0957-4174(95)00047-X.

[28] James, G.A., Wynd, J.G., 1965. Stratigraphic nomenclature of the Iranian oil consortium agreement area. AAPG Bull., 71.

[29] Ji, S.C., Salisbury, M.H., 1993. Shear-wave velocities, anisotropy and splitting in the high grade mylonites. Tectonophysics 221, 453-473 https://doi.org/10.1016/0040-1951(93)90173-H.

[30] Ji, S.C., Wang, Q., Xia, B., 2002. Handbook of Seismic Properties of Minerals, Rocks and Ores. Polytechnic International Press, Montreal, pp. 630.

[31] Kang, Y., Wang, J., 2010. A support-vector-machine-based method for predicting large-deformation in rock mass. Inst. of Rock \& Soil Mech., Chinese Acad. of Sci. 3, 1176-1180. https://doi.org/10.1109/FSKD.2010.5569148.

[32] Kang, Y., Wang, J., 2010. A support-vector-machine-based method for predicting large-deformation in rock mass. Inst. of Rock \& Soil Mech., Chinese Acad. of Sci. 3, 1176-1180. https://doi.org/10.1109/FSKD.2010.5569148.

[33] Kern, H., 1982. P- and S-wave velocities in crustal and mantle rocks under the simultaneous action of high confining pressure and high temperature and the effect of the rock microstructure. In: Schreyer, W. (Ed.), High-Pressure Research in Geosciences. E. chweizerbart'sche Verlagsbuchhandlung, Stuttgart, pp. 15-45.

[34] Malaek, S.M.B., Mollajan, A., Ghorbani, A. and Sharahi, A., 2015. A new system engineering model based on the principles of axiomatic design. J Ind Int Inf, 3(2). https://doi.org/10.12720/jiii.3.2.143-151.

[35] Mangasarian O.L., and Wolberg W.H. (1990). Multisurface method of pattern separaction for medical diagnosis applied to breast cytology. Proceedings of the National Academy of Sciences, 87, 9193-9196. https://doi.org/10.1073/pnas.87.23.9193.

[36] Mangasarian O.L., Setiono R., and Wolberg W.H. (1990). Pattern recognition via linear programming: theory and application to medical diagnosis. Large-Scale Numerical Optimization, 22-30.

[37] Markham I.S. and Ragsdale C.T. (1995). Combining neural networks and statistical predictions to solve the classification problem in discriminant analysis. Decision Sciences, 26(2), 229-242. https://doi.org/10.1111/j.1540-5915.1995.tb01427.x.

[38] Mohammadi, H., Rahmannejad, R., 2009. The estimation of rock mass deformation modulus using regression and artificial neural network analysis Arab. J. Sci. Eng 35 (1A), 67-77.

[39] Niu, W., Li, T., 2010. An Intelligent Rock Mass Classification Method based on Support Vector Machines and the Development of

[40] Niu, W., Li, T., 2010. An Intelligent Rock Mass Classification Method based on Support Vector Machines and the Development of Website for Classification, Information Technology in Geo-Engineering, Proceedings of the 1st International Conference (ICITG), Shanghai.

[41] Patuwo E., Hu M.Y., and Hung M.S. (1993). Two-group classification using neural networks. Decision Sciences, 24(4), 825-845. https://doi.org/10.1111/j.1540-5915.1993.tb00491.x.

[42] Peters G. (1994). Fuzzy linear regression with fuzzy intervals. Fuzzy Sets and Systems, 63, 44-55. https://doi.org/10.1016/0165-0114(94)90144-9.

[43] Rasouli, V., Zacharia, J., Elike, M., 2011. The influence of perturbed stresses near faults on drilling strategy: a case study in Blacktip field North Australia. J. Pet. Sci. Eng. 76, 37-50. https://doi.org/10.1016/j.petrol.2010.12.003.

[44] Rechlin, A.J., Lu“ th, S., Giese, R., 2011. Rock mass classification based on seismic measurements using Support Vector Machines, Harmonising Rock Engineering and the Environment, Chapter 31. CRC Press. https://doi.org/10.1201/b11646-407.

[45] Rechlin, A.J., Lu“ th, S., Giese, R., 2011. Rock mass classification based on seismic measurements using Support Vector Machines, Harmonising Rock Engineering and the Environment, Chapter 31. CRC Press. https://doi.org/10.1201/b11646-407.

[46] Sadooni, N.F., 1993. Stratigraphic sequence, MICROFACIES, and petroleum prospect of the Yamama formation, lower cretaceous, southern Iraq AAPG Bull., 77. https://doi.org/10.1306/BDFF8F92-1718-11D7-8645000102C1865D.

[47] Saemi, M., Ahmadi, M., Yazdian-Varjani, A., 2007. Design of neural networks using genetic algorithm for the permeability estimation of the reservoir. J. Pet. Sci. Eng. 59, 97-105. https://doi.org/10.1016/j.petrol.2007.03.007.

[48] Salchenberger L.M., Cinar E.M., and Lash N.A. (1992). Neural networks: a new tool for predicting thrift failure. Decision Sciences, 23(4), 899-916. https://doi.org/10.1111/j.1540-5915.1992.tb00425.x.

[49] Schrage L (1991). LINDO: An Optimization Modeling System, The Scientific Press, fourth edition.

[50] Sharahi, A., Tehrani, R. and Mollajan, A., 2014. An Axiomatic Model for Development of the Allocated Architecture in Systems Engineering Process. World Academy of Science, Engineering and Technology, International Science Index, Industrial and Manufacturing Engineering, 8(10), pp.3210-3220.

[51] Singh, R., Kainthola, A., Singh, T.N., 2012. Estimation of elastic constant of rocks using an ANFIS approach. Appl. Soft Comput. 12 , 40-45. https://doi.org/10.1016/j.asoc.2011.09.010 
[52] Steinwart, I., 2008. Support Vector Machines. Los Alamos National Laboratory, information Sciences Group (CCS-3). Springer.

[53] Steinwart, I., 2008. Support Vector Machines. Los Alamos National Laboratory, information Sciences Group (CCS-3). Springer.

[54] Subramanian V., Hung M.S., and Hu M.Y. (1993). An experimental evaluation of neural networks for classification. Computers and Operations Research, 20(7), 769-782. https://doi.org/10.1016/0305-0548(93)90063-O.

[55] Suh, N.P., "Axiomatic Design: Advances and Applications", 1st Edition, Oxford University Press, 2001.

[56] Tam K.Y. and Kiang M.K. (1992). Managerial applications of neural networks: the case of bank failure predictions. Management Science, 38(7), 926-947. https://doi.org/10.1287/mnsc.38.7.926.

[57] Tanaka H. and Ishibuchi H. (1992). Possibilistic regression analysis based on linear programming. in J. Kacprzyk and M. Fedrizzi ed., Fuzzy Regression Analysis, 47-60, Physica-Verlag, Heidelberg.

[58] Wantland, D., 1964. Geophysical Measurements of Rock Properties in situ. In: Judd, W.R., (Ed.). State of Stress in Earth's Crust, Proceedings of the International Conference, Santa Monica, California, pp. 409-450.

[59] Wantland, D., 1964. Geophysical Measurements of Rock Properties in situ. In: Judd, W.R., (Ed.). State of Stress in Earth's Crust, Proceedings of the International Conference, Santa Monica, California, pp. 409-450.

[60] Watanabe, T., Kasami, H., Ohshima, S., 2007. Compressional and shear wave velocities of serpentinized peridotites up to 200 MPa. Earth Planets Space 59, 233-244. https://doi.org/10.1186/BF03353100.

[61] Website for Classification, Information Technology in Geo-Engineering, Proceedings of the 1st International Conference (ICITG), Shanghai.

[62] Wilson R.L. and Sharda R. (1994). Bankruptcy prediction using neural networks. Decision Support Systems, 11, 545-557. https://doi.org/10.1016/0167-9236(94)90024-8.

[63] Yasar, E., Erdogan, Y., 2004. Correlating sound velocity with the density, compressive strength and Young's modulus of carbonate rocks. Int. J. Rock Mech. Min. Sci. 41, 871-875. https://doi.org/10.1016/j.ijrmms.2004.01.012.

[64] Zoback, M., 2007. Reservoir Geomechanic, Cambridge University Press, 450p. https://doi.org/10.1017/CBO9780511586477. 